\title{
Morphology, testes development and behaviour of unusual triploid males in microchromosome-carrying clones of Poecilia formosa
}

\author{
D. K. Lamatsch*††, M. Stöck§, R. Fuchs $\|$, M. DöbleR*, R. WackeR*, \\ J. ParzefallII, I. Schlupp** and M. Schartl* \\ *Lehrstuhl für Physiologische Chemie I, Theodor-Boveri-Institute, Biozentrum, Am Hubland, \\ D-97074 Würzburg, Germany, †Institute for Limnology, Austrian Academy of Sciences, \\ A-5310 Mondsee, Austria, §Department of Ecology and Evolution, University of Lausanne, \\ Biophore, CH 1015 Lausanne, Switzerland, \|Department of Organismic Biology, University \\ of Salzburg, A-5020 Salzburg, Austria, IZZoologisches Institut und Museum, Universität \\ Hamburg, Hamburg, Germany and **University of Oklahoma, Department of Zoology, \\ 730 Van Vleet Oval, Norman, OK 73019, U.S.A.
}

(Received 25 May 2009, Accepted 20 July 2010)

\begin{abstract}
In a microchromosome-carrying laboratory stock of the normally all-female Amazon molly Poecilia formosa triploid individuals were obtained, all of which spontaneously developed into males. A comparison of morphology of the external and internal insemination apparatus and the gonads, sperm ploidy and behaviour, to laboratory-bred $F_{1}$ hybrids revealed that the triploid $P$. formosa males, though producing mostly aneuploid sperm, are partly functional males that differ mainly in sperm maturation and sexual motivation from gonochoristic P. formosa males. @ 2010 The Authors Journal of Fish Biology (c) 2010 The Fisheries Society of the British Isles
\end{abstract}

Key words: gonopodium; histology; sex determination; sperm-dependent parthenogenesis.

\section{INTRODUCTION}

The Amazon molly Poecilia formosa (Girard) is a unisexual species of hybrid origin (Hubbs \& Hubbs, 1932; Abramoff et al., 1968; Avise et al., 1991; Schartl et al., 1995a) which reproduces by sperm-dependent parthenogenesis (gynogenesis). Allospecific sperm are needed to trigger the onset of embryogenesis but karyogamy usually does not occur. Therefore, the offspring are natural clones of the mother (Beukeboom \& Vrijenhoek, 1998; Schlupp, 2005; Lampert \& Schartl, 2008). The availability of sperm is an evolutionary limitation for asexual fishes forcing them into close geographic and ecological dependencies with their host, usually a sexually reproducing ancestor (Lamatsch \& Stöck, 2009). Only a few species have evolved 'host switches' (i.e. using sperm from a non-parental species; Choleva et al., 2008) among them $P$. formosa (Niemeitz et al., 2002). It could be predicted that the

\$Author to whom correspondence should be addressed. Tel.: +43 6232 312527; fax: +43 6232 3578; email: dunja.lamatsch@oeaw.ac.at 
evolution of non-sperm-dependent forms would be favoured by selection. On the other hand, rare males occurring in sperm-dependent complexes may enable the persistence of gynogenesis in absence of the host. In the study species, P. formosa, male-like phenotypes have been found in natural habitats, but appear to be rare (Schlupp et al., 1992; Lamatsch, 2001). These rare males in an usually all-female species provide a glimpse into the evolution and function of male-specific genes in a species, in which male-specific genes are no longer under stabilizing selection (Schlupp et al., 1998).

It is known that $P$. formosa may show masculinization to some extent. Three different types of males have been described from the $P$. formosa breeding complex. The first form is 'hormone males' (Haskins et al., 1960; Hamaguchi \& Egami, 1980; Turner \& Steeves, 1989; Schartl et al., 1991): newborn $P$. formosa that were exposed to male hormones pre- and post-partum develop a male phenotype. They show all secondary characteristics as well as behaviour of males, but no fully developed testis is recorded; instead ovo-testis is developed. Offspring have never been reported. The second form is 'pseudomales' or masculinized gynogens (Schlupp et al., 1992): diploid females that are exposed to stress (high population densities, high temperature) may spontaneously develop slightly prolonged anal fin rays 3, 4 and 5 as this is the case when males develop their copulatory organ, the gonopodium. These fish, however, are unable to move their anal fin, as during gonopodial thrusting, probably due to lack of a male-specific muscle operating the gonopodial suspensorium. Again offspring from these fish have never been reported. The third form is triploid males with microchromosomes (Lamatsch et al., 2000a): in laboratory strains which carry microchromosomes derived probably from one of the short fin mollies like P. mexicana or Poecilia sphenops Valenciennes males spontaneously occur without any apparent external trigger (e.g. high population densities, high temperature and skewed sex ratios). These fish show a black pigmentation pattern due to the macromelonophore locus located on the microchromosomes (Schartl et al., 1997). Cytogenetic and genetic analyses revealed that these males were allotriploids, which produce sperm but show irregularities in meiotic chromosome pairing (Lamatsch et al., 2000a).

In the present study, 16 triploid $P$. formosa males spontaneously occurring over a period of 9 years were investigated, corresponding to an overall frequency of considerably $<1 \%$. Since there was no obvious external trigger, the aim was to understand how spontaneous male production in an 'all-female species' might occur, the evolutionary significance this might have for the breeding complex, and how these males differ from the aforementioned 'hormone males' and 'pseudomales'.

Primary and secondary sexual characters, as well as sexual behaviour in these unusual triploid $P$. formosa males were analysed and compared with artificially bred $\mathrm{F}_{1}$ hybrids between Poecilia latipinna (Le Sueur) females and Poecilia mexicana Steindachner males for the following reasons: 1) P.formosa is a hybrid species (Hubbs \& Hubbs, 1932; Turner et al., 1980; Avise et al., 1991; Schartl et al., 1995a), derived from the natural hybridization between a $P$. mexicana female and a $P$. latipinna male $(P$. formosa $=P$. mexicana $\times P$. latipinna $) ; 2)$ the triploid $P$. formosa males show the following genetic composition: [(P. mexicana $\times$ P. latipinna $)+$ microchromosome $\times$ Poecilia salvatoris Regan or P. mexicana limantouri (see Table I); 3) $\mathrm{F}_{1}$ hybrids originated by crossing the two parental species $P$. latipinna and $P$. mexicana. The resulting offspring are bisexual diploid hybrids 
TAble I. Descent of triploid Poecilia formosa males

\begin{tabular}{lll}
\hline Male & Female stock & \multicolumn{1}{c}{ Father } \\
\hline $1-6,8,14,15$ & Pf 922 & Poecilia salvatoris \\
7,16 & Pf 922 & Poecilia mexicana limantouri \\
9 & Pf 637 & P. salvatoris \\
10,12 & Pf 533 & P. salvatoris \\
11 & Pf 1587 & P. mexicana limantouri \\
13 & Pf 537 & P. salvatoris \\
\hline
\end{tabular}

(males and females; Ptacek, 2002). Some of these hybrids, however, show irregularities in meiosis which has been identified as automixis (Lampert et al., 2007).

Therefore, $\mathrm{F}_{1}$ hybrid males are genetically closer to the triploid P. formosa males than either of the parental species. Hence, the prediction was that triploid P. formosa males would not strongly differ in sexual characters from sexual (hybrid) males.

In the present study, this hypothesis was tested. The results showed that the triploid $P$. formosa males did not differ significantly from gonochoristic males in morphology and mate choice towards different types of stimuli (selectivity), but do reveal pronounced differences in testes maturation, and exhibited reduced sexual activity (motivation). Due to their ability to produce sperm and trigger embryogenesis in gynogenetic females, the occurrence of similar males in natural habitats might enable $P$. formosa to become independent from their sexual hosts.

\section{MATERIALS AND METHODS}

\section{FISHES}

All fishes were raised and maintained under standard conditions as described for Xiphophorus maculatus (Günther) (24-27 $\mathrm{C}, 14 \mathrm{~L}: 10 \mathrm{D}$ cycle) (Kallman, 1975) in the aquarium of the Biocenter at the University of Würzburg, Germany. Twenty to 50 fishes were kept in $501 \mathrm{com}$ munity tanks with shared water. All phenotypic males [Fig. 1(c)-(e) and Table I] developed spontaneously in clonal lines of spotted females [Fig. 1(b)] carrying two to three microchromosomes (Schartl et al., 1995b) from matings either with P. sphenops males [Fig. 1(a)] or P. mexicana males [Fig. 1(g)]. They are derived from the following strains.

Black Amazon I (WLC 533): Animals of this clonal line exhibit a black spotted pigmentation phenotype because of the presence of a microchromosome derived from a $P$. sphenops. The founder female was from wild-type pigmented $P$. formosa strain I (WLC1357). The introgression event and origin of this line have been described in Schartl et al. (1995b). Several clonal sublines of WLC 533 were established (e.g. 537, 637).

Black Amazon II (WLC 922): the clonal line is similar to WLC 533, also originating from an independent introgression event of a $P$. sphenops-derived microchromosome into P. formosa strain I (WLC1357). Several clonal sublines of WLC 922 were established (e.g. 1587).

Black molly (WLC 1351): the melanistic ornamental strain is of unknown genetic origin. From body shape and mitochondrial DNA sequence, it is probably derived from the P. mexicana and P. sphenops complex (B. Wilde \& M. Schartl, unpubl. data). These fishes are homogeneously dark black coloured due to the presence of macromelanophores in the skin of the body and fins. Fishes are homozygous for the dominant pigmentation loci niger (N) and melas (M) (Schröder, 1964).

Liberty mollies are an aquarium strain derived from $P$. salvatoris.

For maintaining the gynogenetic stocks, usually one male per tank per 20 to 30 P. formosa was used (Lamatsch et al., 2009). 

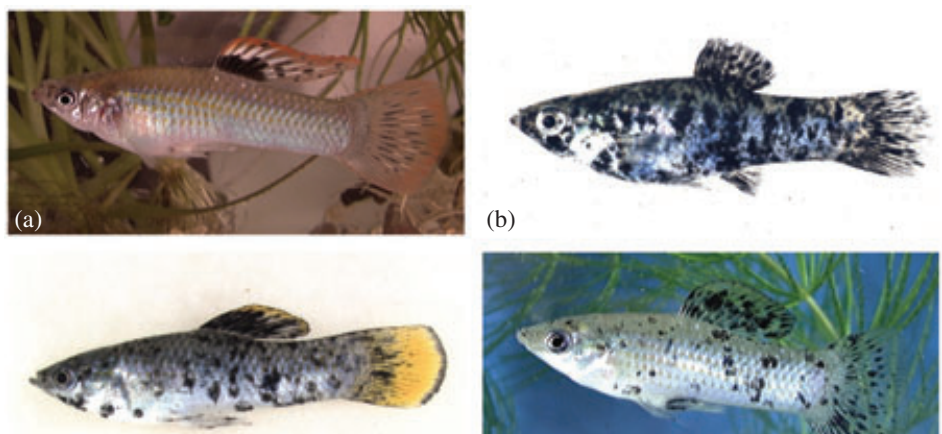

(c)
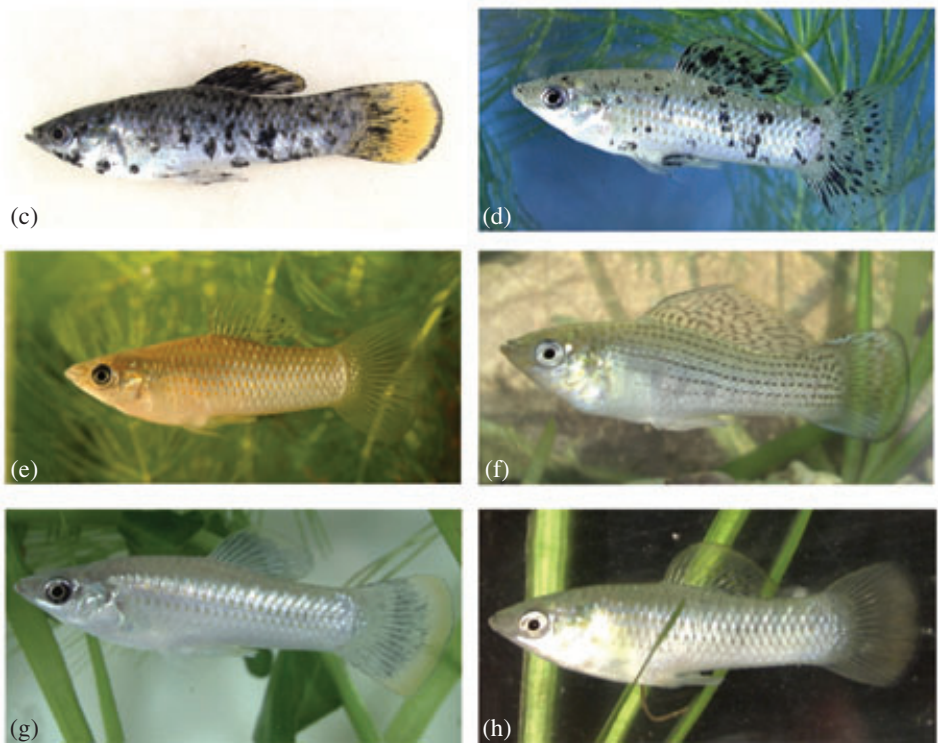

FIg. 1. Habitus of (a) a Poecilia salvatoris male and (b) a typical spotted female carrying microchromosomes in comparison to (c)-(e) three Poecilia formosa males showing different levels of pigmentation. (f)-(h) Show gonochoristic males: (f) a Poecilia latipinna male, (g) a Poecilia mexicana male and (h) a hybrid male resulting from breeding a $P$. latipinna female with a $P$. mexicana male.

The ploidy of $P$. formosa males was measured by flow cytometry (Lamatsch et al., 2000b) as soon as phenotypic changes (e.g. prolongation of the anal fin) were detected. Triploid status was shown for all males (Lamatsch et al., 2000a).

For comparisons of all investigated traits, $\mathrm{F}_{1}$ hybrids $(P$. latipinna $\times P$. mexicana $)$ were used [Fig. 1(h)]. These $F_{1}$ hybrids are bisexual and fertile (Ptacek, 2002; Lampert et al., 2007). Poecilia latipinna males [Fig. 1(f)] and P. mexicana males [Fig. 1(g)] were used as additional control if available.

\section{BREEDING EXPERIMENTS}

A previous publication already demonstrated some sperm production in these triploid P. formosa males (Lamatsch et al., 2000a). Therefore, males were mated to groups of four to five spotted and wild-type coloured $P$. formosa females as well as to sexual $P$. mexicana females to test their fertility. All females were virgin as poeciliids are able to store sperm. Breeding success (production of fry) was recorded.

\section{HABITUS AND ANATOMY OF SECONDARY SEXUAL CHARACTERISTICS}

The standard length $\left(L_{S}\right)$ and habitus of all males were assessed and photographed. The structure of the insemination apparatus (gonopodium, consisting of rays 3-6 of the anal fin 
with the attached appendices) and the anatomy of the gonopodial suspensorium (internal anal fin rays where the male-specific muscles insert to move the gonopodium) were visualized using the Spalteholz/Dawson technique (Dawson, 1926). Briefly, the soft tissues was cleared with $3 \%$ potassium hydroxide for 3 days at room temperature, followed by the staining of bones with $0.3 \%$ alizarin red/3\% potassium hydroxide, and the replacement of body fluids with glycerol (Culling, 1963). Images were taken with a Stemi SV 11 stereo microscope (Zeiss; www.zeiss.de). Five individuals of triploid $P$. formosa males were compared to five $\mathrm{F}_{1}$ hybrid males and seven $P$. mexicana males were used as additional control.

\section{HISTOLOGY OF TESTES}

For histological examination of testes, the material was fixed for at least 5 days in $4 \%$ formaldehyde buffered in $1 \times$ PBS. Sections were routinely stained with haematoxylin and eosin (HE) and mounted in Rotihistokitt (Roth; www.carl-roth.de). Analyses were performed and images taken with an Axiophot POL microscope (Zeiss).

\section{DNA CONTENT OF TESTIS CELLS}

In order to obtain easily measurable monolayers of nuclei, fresh imprints of cross-sections of testes were prepared on microslides (Polysine adhesive). Testis imprints from a triploid $P$. formosa male and a P. mexicana male were prepared on the same microslide. All slides were then processed through the Feulgen reaction as described elsewhere (Klapperstück \& Wohlrab, 1996; Stöck \& Grosse, 1997; Stöck et al., 2002). Relative measurements of the integrated optical density (IOD), which is referred to as DNA content (C-value), were made with the CYDOK image analysis system (Hilgers; www.hilgers.com) at a wavelength of $546 \mathrm{~nm}$. To document stages of spermatogenesis 100 testis nuclei from each male were measured. Nuclei from the testis imprints of each fish were randomly chosen by the operator on the live microscopic screen image and measured using the DNA content of somatic nuclei as standard. The DNA content of the haploid sperm nuclei of the diploid P. mexicana male was used as internal (i.e. slide-specific) relative reference value. Images were taken with Leitz DM RBE microscope (20-100×), Leica camera (www.leica.com) and Kodak Elite 200 ASA film (www.kodak.com).

\section{BEHAVIOUR}

To assess components of the sexual behaviour of unusual triploid $P$. formosa males, mate choice tests were performed and compared to the behaviour of genetically similar diploid hybrid $\mathrm{F}_{1}$ males by presenting them pairs of females as well as a mixed male-female pair as stimuli. All possible stimulus combinations between $P$. formosa, $P$. latipinna and $P$. mexicana were used. Choice tests were performed as described in Schlupp \& Ryan (1996) with slight modifications. Two different types of behavioural tests were conducted: in one test, only visual information was available to the focus individual (visual choice test) and in the other test, the fishes were allowed to interact unrestricted in the tank (full contact choice test). Stimulus fishes were chosen randomly from stock cultures (c. five tanks per species with c. 30-50 fish each) and put back after use. Each time a different stimulus pair was used to avoid possible preferences for a single stimulus fish. Each stimulus pair consisted of fishes of identical $L_{\mathrm{S}}( \pm 2 \mathrm{~mm})$ since larger females are usually preferred regardless of species (Gabor \& Aspbury, 2008). For full contact choice tests, females were chosen to be non-receptive by eye, i.e. not extensively followed by a male in stock tank (Parzefall, 1973) and without an anal spot (Peden, 1973), because receptive females will always be preferred regardless of species (Schlupp et al., 1991).

Size ranges of fishes used in mate choice experiments are given in Appendix I. Male poeciliids stop growing as soon as they reach sexual maturity, whereas females grow lifelong (Bisazza, 1993). Therefore, females are in general larger than males. Since male mate choice was tested, the stimulus fishes were mostly female, the focus fish male. It can be seen from Appendix I, however, that triploid P. formosa males did not differ significantly in $L_{\mathrm{S}}$ from 
hybrid males $(P>0.05)$ and that the $L_{\mathrm{S}}$ range of stimulus fishes is within natural size distributions (Appendix I). The sequence of the stimulus pairs was randomly chosen for each male tested. Each focus male performed five visual choice tests and four full contact choice tests (plus repeated trials), unless the fish died before the trials were finished. Eleven to 12 triploid P. formosa males and seven diploid $\mathrm{F}_{1}$ hybrid males were tested. Fishes were kept in a shared water system. The triploid males were raised in a group tank (25 1) with spotted and unspotted siblings. The $\mathrm{F}_{1}$ hybrid males were raised with unspotted siblings. All males were isolated for at least $24 \mathrm{~h}$ prior to trials to standardize sexual motivation (Franck, 1975; Travis, 1994).

The motivation to study male mating behaviour was to understand the full impact of the masculinization observed in this study. Especially in light of the hypothesis that these males might make $P$. formosa independent of sperm donors, it is crucial to know whether or not the masculinized $P$. formosa will actually mate with conspecifics, or if their mating behaviour remains that of females, or if their behaviour is somehow confused.

In addition to full contact choice tests, visual choice tests were performed. These have the advantage of disentangling the 'male' sexual preferences from the actual interactions measured in full contact trials. While full contact trials will allow the behavioural interactions that may lead to matings (including the female response to male approaches) to be studied, the visual choice tests remove the interactive component and allow the preference only to be investigated. This is important because this probably directly reflects the effects of the spontaneous masculinizations under investigation here. These visual choice experiments were conducted as described in Schlupp et al. (1994) with slight modifications (see Appendix I).

In trials allowing full interaction, the male was placed with the two stimulus fishes in an 181 tank $(41.5 \times 28 \times 16 \mathrm{~cm})$. For acclimatization, the male was placed in a Plexiglas spawning box for $10 \mathrm{~min}$ followed by a 10 min observation period (Altmann, 1974) in which the behavioural elements 'following', 'nipping' and 'copulation (attempts)' (Parzefall, 1969) were recorded as 'events', and presence or absence of 'courtship behaviour' was noted. Nipping appears to aid a male in determining a female's reproductive condition (Parzefall, 1973; Travis \& Woodward, 1989; Travis, 1994). In full contact choice tests, only four different trials were performed (one to four; see Appendix I). Poecilia mexicana male $v$. P. mexicana female (5) was omitted since direct contact of males would only lead to aggression behaviour. In total, seven diploid $\mathrm{F}_{1}$ hybrid males and 12 triploid $P$. formosa males were tested.

\section{DATA ANALYSIS}

For each male type, two different aspects regarding sexual behaviour were analysed. As mentioned above, the individuals could freely choose between two different stimuli during experiments. In the different trials of the visual choice test, the times spent in front of each stimulus fish were recorded, whereas the frequency of different elements of sexual behaviour towards the different females was recorded in the full contact test (i.e. number of following, nipping and copulation attempts). The raw data are given in Appendices II, III and IV.

The total amount of behavioural events, e.g. sum of times spent in front of both stimuli fishes $\left(t_{1}+t_{2}\right)$, or total number of following, nipping and copulation attempts $\left(n_{1}+n_{2}\right)$, was used as a measure for 'motivation'. To measure 'selectivity', the difference between the two stimuli divided by the total amount of behavioural events $\left(t_{1}-t_{2}\right)\left(t_{1}+t_{2}\right)^{-1}$ was utilized, a procedure which mapped the possible values into an interval between -1 and +1 . A value of +1 would mean full preference towards stimulus 1 , and -1 vice versa for stimulus 2 .

Motivational components of behaviour were tested with a repeated-measures ANOVA (visual choice) and the Friedman test (group means and full contact). For statistical analysis of selectivity, preferences towards stimuli were coded into a dichotomous (binary) variable, which could not be tested with an ANOVA design, and was therefore tested with a binomial test against a proportion of $P=0 \cdot 5$, i.e. random choice of stimuli, for each trial separately. The whole sequence of trials was tested with a Cochrane Q-test. Data analysis was performed with SPSS (SPSS Inc.; www.spss.com) and R (R Development Core Team, 2008; www.r-development-core-team.software.informer.com). 


\section{RESULTS}

\section{BREEDING EXPERIMENTS}

A previous publication already showed that the triploid $P$. formosa males in principle could provide the necessary stimulus to trigger parthenogenetic embryogenesis of unreduced diploid eggs in gynogenetic females due to the presence of sperm (Lamatsch et al., 2000a). To study the extent of the reproductive capacity in more detail, 16 males were individually mated with spotted and wild-type $P$. formosa females. Offspring were obtained from only five males mostly with spotted P. formosa. The offspring did not exhibit any signs of paternal contribution (body colouration and karyotype). No offspring were ever obtained with sexual P. mexicana.

\section{HAB ITUS}

The pigmentation of the $P$. formosa phenotypic males ranged from heavily black spotted to uniformly grey, wild-type coloured [see Fig. 1(c)-(e)]. The spotted pigmentation patterns indicated that the microchromosomes were still present (Nanda et al., 2007) which has also been shown by karyotyping (Lamatsch et al., 2000a). Even the darkest males, however, never reached the degree of pigmentation of normal diploid females of the same stock [Fig. 1(b)]. At sexual maturity, most of the phenotypic $P$. formosa males displayed an intensely yellow colouration of the dorsal and tail fin. In general, they had the typical body proportions of males (estimated by eye) according to Ptacek (2002). The $F_{1}$ hybrid males also showed the typical male body proportions and the yellow colour of dorsal fin and tail fin at sexual maturity (Parzefall, 1969). All phenotypic males $(n=16)$ were triploid with at least one microchromosome as determined by flow cytometry and cytogenetics, whereas all their sisters investigated were diploid $(n=50)$.

\section{ANATOMY OF SECONDARY SEXUAL CHARACTERISTICS}

The suspensoria of $P$. formosa males $(n=5)$ showed two gonapophyses and normal gonactinostal complex with baseosts [Fig. 2(a) and Table II]. The gonopodia of $P$. formosa males [Fig. 2(b)] showed all features of the structures seen in gonochoristic males (Table II). In detail, ray 3 of the gonopodia showed ventral spines and eight to 12 subdistal serrae. Ray 4 split into $4 \mathrm{a}$ and $4 \mathrm{p}$. The $4 \mathrm{p}$ showed 10 to 12 double subdistal serrae and the tip of $4 p$ was bent down. Ray $5 p$ ended in a double bony claw in males 3, 5 and 7, and in a single bony claw in males 4 and 6 . Ray 6 was shorter than rays 3, 4 and 5. Each male had a membranous hook on ray 3 and a palp of variable size. In contrast to 'hormone males' (Schlupp et al., 1992), every male was able to flap the gonopodium to the front (gonopodial thrusting) showing that the requisite muscles for successful insemination were developed. The triploid $P$. formosa males did not show any of the malformations of gonopodial structures which have frequently been seen in interspecies hybrids of poeciliids (Rosen \& Bailey, 1963).

The diploid $\mathrm{F}_{1}$ hybrid males $(n=5)$ also showed two gonapophyses (except one male which showed three gonapophyses) and normal gonactinostal complex 
[Fig. 2(c)]. Gonopodia were normally developed [Fig. 2(d)]. One male showed a single bony claw on ray $5 p$ in contrast to the normal double structure. Ray $4 p$ was slightly bent down at its tip and possessed nine to 11 subdistal serrae. Ray 3 showed ventral spines, nine to 11 subdistal serrae, a membranous hook and the palp. Ray 6 was shorter than rays 3, 4 and 5 (Table II).

As in P. mexicana males $[n=7$; Fig. 2(e)], all gonopodia of the triploid $P$. formosa males featured a gonopodial palp and a double bony claw on $5 \mathrm{p}$ (except male M1), 10 to 13 subdistal serrae on ray $4 p$ which tip was slightly bent down. On ray $3, P$. mexicana males showed ventral spines and eight to 11 subdistal serrae and a membranous hook. Ray 6 was shortened in comparison to rays 3, 4 and 5 [Fig. 2(f) and Table II]. In summary, triploid P. formosa males did not differ considerably from normal gonochoristic males in their anatomy of secondary sexual characters.

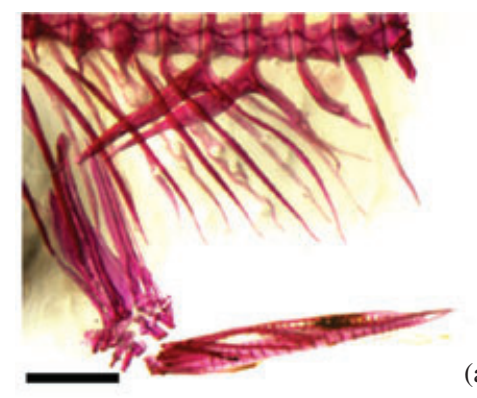

(a)

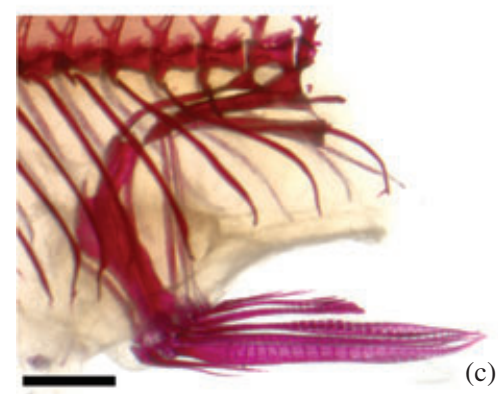

(c)

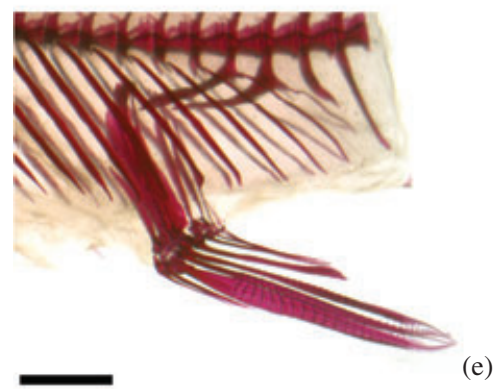

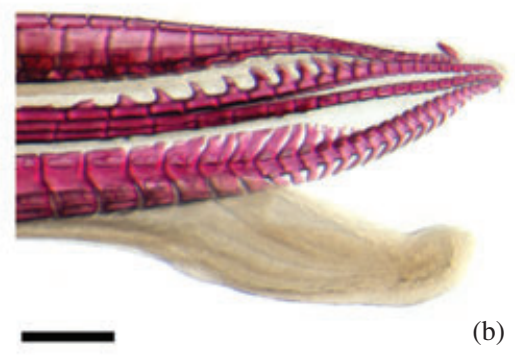

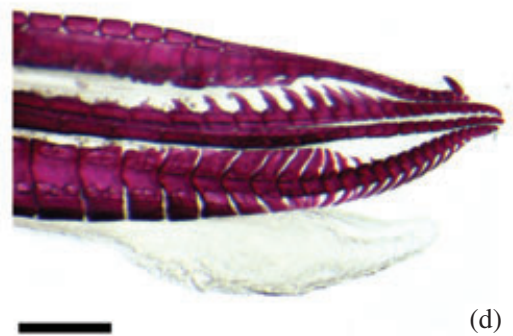

(d)

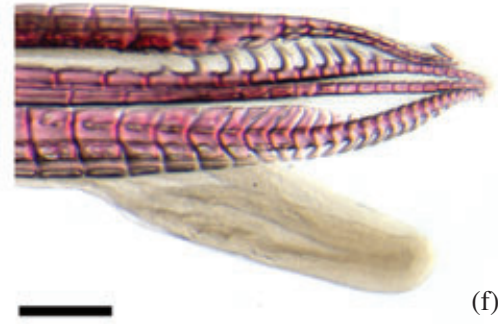

FIG. 2. (a) Suspensorium and (b) gonopodium of a triploid Poecilia formosa male in comparison to (c), (d) a hybrid male and (e), (f) a Poecilia mexicana male visualized by the Spalteholz/Dawson technique. Bar represents $2 \mathrm{~mm}$ for (a), (c) and (e) and $400 \mu \mathrm{m}$ for (b), (d) and (f). 
TABLE II. Analysis of the variable characters of the complex insemination apparatus of triploid Poecilia formosa males in comparison to hybrid males and Poecilia mexicana males. Transformed rays of gonopodium (3-5) are numbered from bottom to top. Rays 4 and 5 are split into $4 \mathrm{a}$ and $4 \mathrm{p}$ and $5 \mathrm{a}$ and $5 \mathrm{p}$ (see also Fig. 2)

\begin{tabular}{|c|c|c|c|c|}
\hline Individual & $\begin{array}{c}5 \mathrm{p} \text { with } \\
\text { bony claw }\end{array}$ & $\begin{array}{l}\text { Subdistal } \\
\text { serrae } 4 p\end{array}$ & $\begin{array}{c}\text { Subdistal } \\
\text { serrae on } 3\end{array}$ & Gonapophyses \\
\hline P. formosa male 3 & $+($ double $)$ & 11 (double) & 8 & 2 \\
\hline P. formosa male 4 & $+($ single $)$ & 10 (double) & 12 & 2 \\
\hline P. formosa male 5 & $+($ double $)$ & 10 (double) & 9 & 2 \\
\hline P. formosa male 6 & $+($ single $)$ & 11 (double) & 11 & 2 \\
\hline P. formosa male 7 & $+($ double $)$ & 12 (double) & 10 & 2 \\
\hline Hybrid male 1 & $+($ double $)$ & 11 (double) & 12 & 2 \\
\hline Hybrid male 3 & $+($ double $)$ & 10 (double) & 11 & 2 \\
\hline Hybrid male 4 & $+($ single $)$ & 11 (double) & 12 & 3 \\
\hline Hybrid male 5 & $+($ double $)$ & 9 (double) & 12 & 2 \\
\hline Hybrid male 6 & $+($ double $)$ & 9 (double) & 10 & 2 \\
\hline P. mexicana male 1 & $+($ double $)$ & 10 (double) & 9 & 2 \\
\hline P. mexicana male 2 & $+($ double $)$ & 13 (double) & 11 & 2 \\
\hline P. mexicana male 3 & $+($ double $)$ & 12 (double) & 10 & 2 \\
\hline P. mexicana male 4 & $+($ double $)$ & 10 (double) & 9 & 2 \\
\hline P. mexicana male 5 & $+($ double $)$ & 10 (double) & 8 & 2 \\
\hline P. mexicana $\mathrm{M} 1 *$ & $+($ double $)$ & 10 (double) & + & 2 \\
\hline P. mexicana M2* & $+($ single $)$ & 9 (double) & + & 2 \\
\hline
\end{tabular}

*Data from Döbler (1998); +, present.

\section{HISTOLOGY OF TESTES}

In gonochoristic Poecilia males, the lobules terminate at the periphery of the testis, where spermatogonia are located. Proceeding proximally, meiotic germ cells are arranged between lightly staining Sertoli cells, and primary spermatocytes, spermatids and mature spermatozoa are observed in the lumen of the testis. In contrast to hormone males which often show ovotestes (Turner \& Steeves, 1989; Schartl et al., 1991), the gonads of the $P$. formosa males were always testis-like and showed paired morphology. Cross-sections of testes, however, showed clear differences between triploid $P$. formosa males and diploid gonochoristic males (Fig. 3). Spermatogonia and spermatocytes are present in the P. formosa males [Fig. 3(a)-(d)] but the proportion of mature spermatozoa and spermatozeugmata was drastically reduced in comparison to $\mathrm{F}_{1}$ hybrid males [Fig. 3(e), (f)] or P. latipinna males [Fig. 3(g), (h)]. This is consistent with the observation that $P$. formosa males do not have as many offspring as gonochoristic males (Lamatsch et al., 2000a; this study).

\section{DNA CONTENT OF TESTIS CELLS}

Flow cytometric measurements of ripe sperm led to the conclusion that aneuploid sperm is produced (Lamatsch et al., 2000a). Therefore, different stages of spermatogenesis were investigated by measuring relative DNA content on fresh testis imprints. The results show that spermatogenesis of triploid P. formosa was 

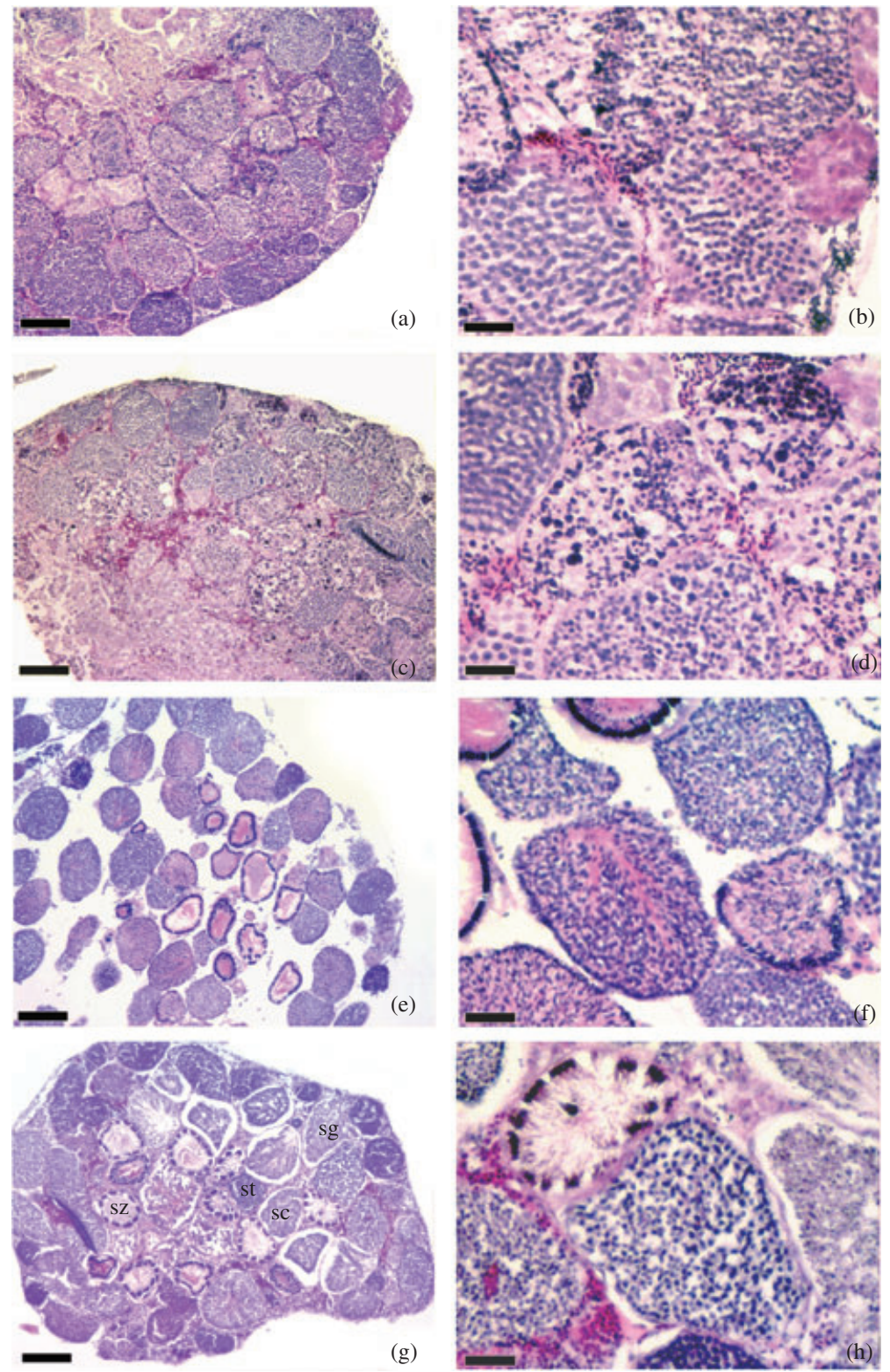

FIG. 3. Haematoxylin and eosin staining on paraffin sections of testis tissue of triploid Poecilia formosa male number 5 (a), (b) and number 3 (c), (d) in comparison to a (e), (f) a hybrid male and (g), (h) P. latipinna male. Note that ripe spermatozoa are missing from the (a)-(d) triploid P. formosa males. Sg, spermatogonia; Sc, spermatocytes; St, spermatids; Sz, sperm bundles. Bar represents $100 \mu \mathrm{m}$ for (a), (c), (e) and (g) and $25 \mu \mathrm{m}$ for (b), (d), (f) and (h).

highly abnormal [Fig. 4(a)]. The C-value of somatic and spermatogonial nuclei was $3 \mathrm{C}$ as expected and a few nuclei of $6 \mathrm{C}$ cells were observed in some preparations representing the somatic mitotic G2 phases. Later stages of spermatogenesis, however, showed a variety of DNA contents ranging from $<0.5 \mathrm{C}$ to $>1.8 \mathrm{C}$, 


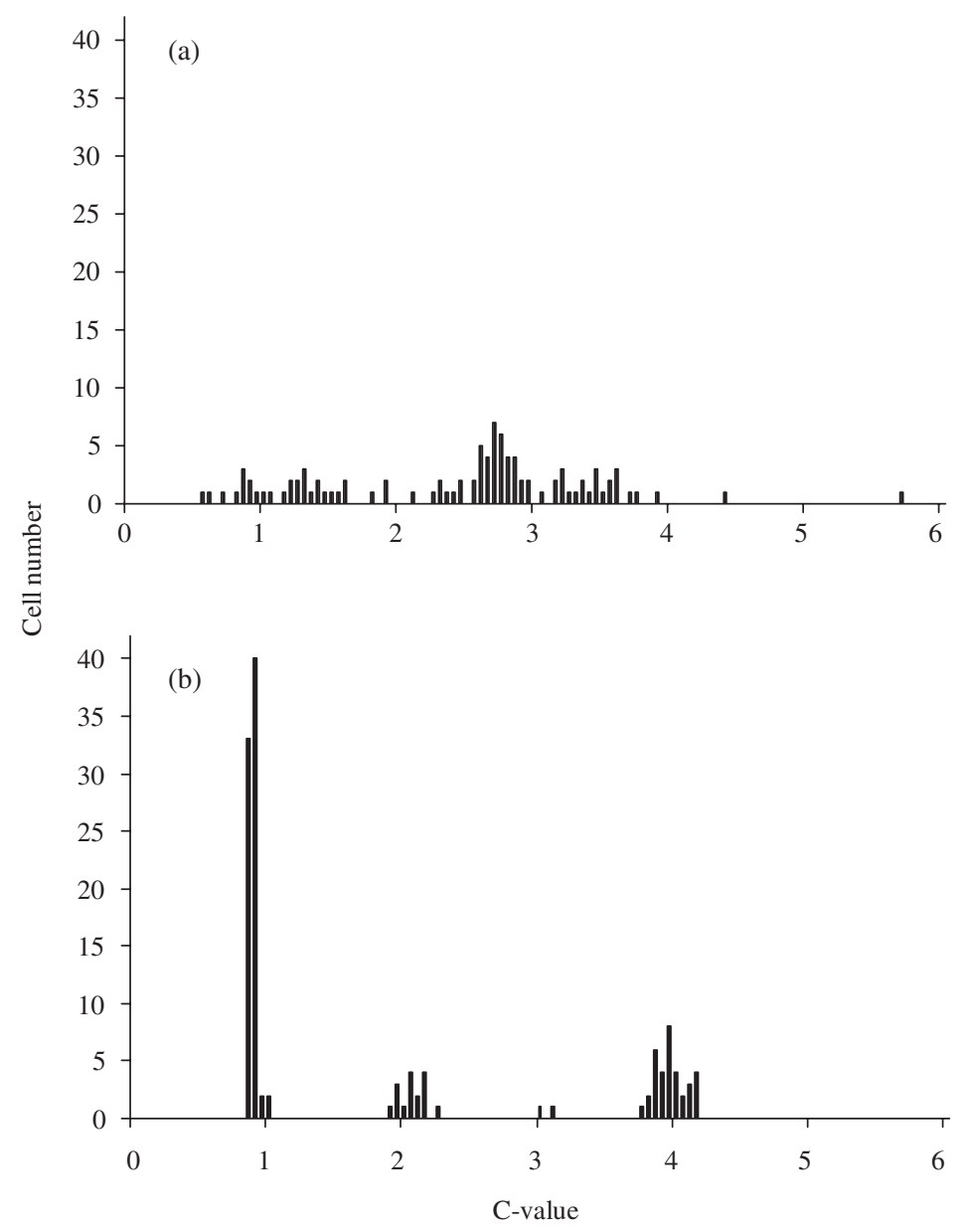

FIG. 4. Histograms of values of the relative measurements of the integrated optical density in stages of spermatogenesis in testis imprints of a (a) triploid Poecilia formosa male and (b) diploid Poecilia mexicana male.

indicating aneuploidy. Also, form and size of sperm nuclei varied much more in the triploid P. formosa males [Fig. 5(b), (c)] than in the diploid P. mexicana [Fig. 5(a)]. In P. mexicana males, the $2 \mathrm{C}$ spermatogonial cells reduplicate their DNA content and enter meiosis $\mathrm{I}$ in a $4 \mathrm{C}$ stage. After completion of meiosis I, their DNA content is $2 \mathrm{C}$ again and the expected haploid stage of euploid sperm is reached after meiosis II [Fig. 4(b)]. The sperm nuclei of these normal males show a distinctly more compact form and equal size [Fig. 5(a)] than of P. formosa males [Fig. 5(b), (c)].

\section{BEHAVIOUR}

Results for visual preference tests are given (Appendix V and Fig. A1). In addition to visual preference tests, full contact choice tests were performed giving the fishes 

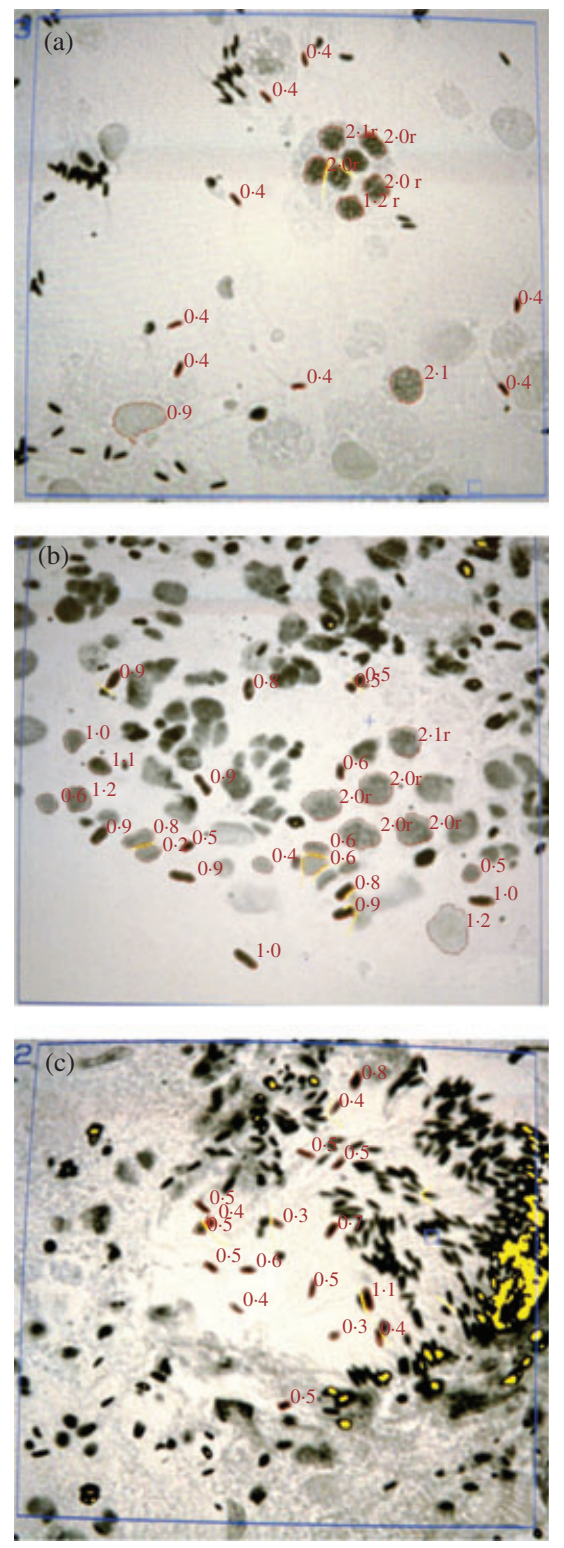

FIG. 5. Screen shots of a tissue imprint of a testis of (a) a sexual diploid Poecilia mexicana male in comparison with that of (b), (c) two unusual Poecilia formosa males. Each image shows the (relative) ratios of DNA contents as revealed by Feulgen densitometry using the image analysis system CYDOK. Somatic nuclei are used as 'reference nuclei' (always '2.0'), the DNA content of all other cells is shown as relative value. (a) 2.1/2.0: DNA content of somatic nuclei (diploid); 0.9-1.2: relative DNA content (haploid) of stages of spermatogenesis; 0.5-0.4: 'high density' sperm nuclei as reached after completion of spermiohistogenesis. Note the almost constant value of the sperm DNA content. (b) 2.0: DNA content of somatic nuclei (triploid); 0.4-0.9: 'high density' sperm nuclei as reached after completion of spermiohistogenesis. Note the large range of value of the sperm DNA content suggesting aberrant and aneuploid sperm. (c) 2.0: DNA content of somatic nuclei (triploid; outside the screen); 0.3-1.1: 'high density' sperm nuclei as reached after completion of spermiohistogenesis. Note the large range of value of the sperm DNA content suggesting aberrant and aneuploid sperm. 
TABLE III. Choice preferences of diploid $\mathrm{F}_{1}$ hybrid males and triploid Poecilia formosa males concerning the three behavioural elements measured in the full contact tests: (a) following, (b) nipping and (c) copulation (attempts) (see Appendix III)

\begin{tabular}{|c|c|c|c|c|c|c|c|}
\hline Trial & Stimulus & $\begin{array}{c}n \\
\text { (diploid) }\end{array}$ & $\begin{array}{c}\text { Binomial } \\
P\end{array}$ & $\begin{array}{c}n \\
\text { (triploid) }\end{array}$ & $\begin{array}{c}\text { Binomial } \\
P\end{array}$ & $\begin{array}{c}n \\
\text { (all) }\end{array}$ & $\begin{array}{c}\text { Binomial } \\
P\end{array}$ \\
\hline \multicolumn{8}{|c|}{ (a) Following } \\
\hline \multirow[t]{2}{*}{1} & Poecilia formosa & 2 & $>0.05$ & 4 & $>0.05$ & 6 & $>0 \cdot 05$ \\
\hline & Poecilia latipinna & 5 & & 6 & & 11 & \\
\hline \multirow[t]{2}{*}{2} & P. formosa & 2 & $>0 \cdot 05$ & 5 & $>0.05$ & 7 & $>0.05$ \\
\hline & Poecilia mexicana & 5 & & 5 & & 10 & \\
\hline \multirow[t]{2}{*}{3} & P. latipinna & 4 & $>0 \cdot 05$ & 8 & $>0.05$ & 12 & $>0.05$ \\
\hline & P. mexicana & 3 & & 2 & & 5 & \\
\hline \multirow[t]{2}{*}{4} & Spotted & 0 & $<0.05$ & 3 & $>0.05$ & 3 & $<0.05$ \\
\hline & Unspotted & 7 & & 7 & & 14 & \\
\hline \multicolumn{2}{|c|}{ Cochran Qd.f. $=3$} & 7 & $>0.05$ & 10 & $>0.05$ & 17 & $>0 \cdot 05$ \\
\hline \multicolumn{8}{|c|}{ (b) Nipping } \\
\hline \multirow[t]{2}{*}{1} & P. formosa & 5 & $>0.05$ & 5 & $>0.05$ & 10 & $>0.05$ \\
\hline & P. latipinna & 2 & & 3 & & 5 & \\
\hline \multirow[t]{2}{*}{2} & P. formosa & 2 & $>0.05$ & 4 & $>0.05$ & 6 & $>0.05$ \\
\hline & P. mexicana & 5 & & 4 & & 9 & \\
\hline \multirow[t]{2}{*}{3} & P. latipinna & 3 & $>0.05$ & 4 & $>0.05$ & 7 & $>0 \cdot 05$ \\
\hline & P. mexicana & 4 & & 3 & & 7 & \\
\hline \multirow[t]{2}{*}{4} & Spotted & 0 & $<0.05$ & 3 & $>0.05$ & 3 & $<0.05$ \\
\hline & Unspotted & 7 & & 5 & & 12 & \\
\hline \multicolumn{2}{|c|}{ Cochran Qd.f. $=3$} & 7 & $<0 \cdot 05$ & 5 & $>0.05$ & 12 & $<0.05$ \\
\hline \multicolumn{8}{|c|}{ (c) Copulation (attempts) } \\
\hline \multirow[t]{2}{*}{1} & P. formosa & 4 & $>0.05$ & 4 & $>0.05$ & 8 & $>0 \cdot 05$ \\
\hline & P. latipinna & 3 & & 0 & & 3 & \\
\hline \multirow[t]{2}{*}{2} & $P$. formosa & 2 & $>0.05$ & 1 & $>0.05$ & 3 & $>0.05$ \\
\hline & P. mexicana & 4 & & 3 & & 7 & \\
\hline \multirow[t]{2}{*}{3} & P. latipinna & 4 & $>0 \cdot 05$ & 2 & $>0.05$ & 6 & $>0.05$ \\
\hline & P. mexicana & 3 & & 3 & & 6 & \\
\hline \multirow[t]{2}{*}{4} & Spotted & 0 & $<0.05$ & 2 & $>0.05$ & 2 & $<0.05$ \\
\hline & & 7 & & 34 & & 10 & \\
\hline \multicolumn{2}{|c|}{ Cochran Qd.f. $=3$} & 6 & $>0 \cdot 05$ & 2 & $>0.05$ & 8 & $<0 \cdot 05$ \\
\hline
\end{tabular}

the opportunity not only to perceive visual signals but also chemical and tactile cues, corresponding to other important sensory systems in fishes (Franck \& Geissler, 1973). Again, diploid $F_{1}$ hybrids showed a higher motivation to perform different types of sexual behaviour (see Fig. 6 and Table III). Testing the groups' means with the Friedman test yielded significant differences concerning the number of nipping and copulations attempts (both d.f. $=1, P<0.05$ ), whereas the difference in following behaviour was not significant $(P>0 \cdot 05$; Table IV).

There were no significant differences in choice between the two groups in trials 1-3, but the clear preference of diploid $F_{1}$ hybrids for wild-type mates in trial 4 (Fig. 6). Accordingly, no copulation attempt towards a spotted female was 

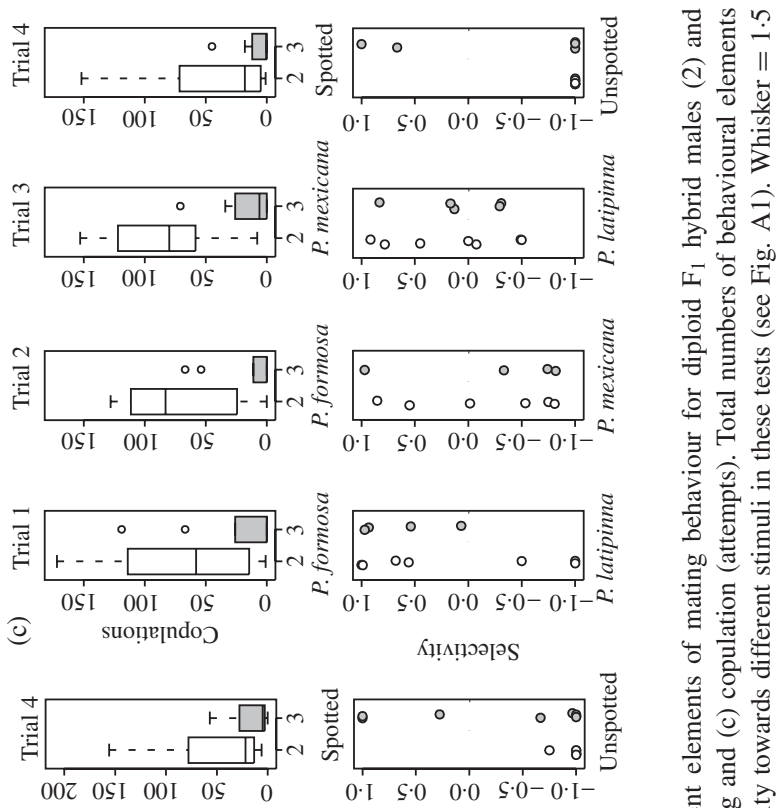

厌䓃这

응 है

홍

동

宊

흥 :

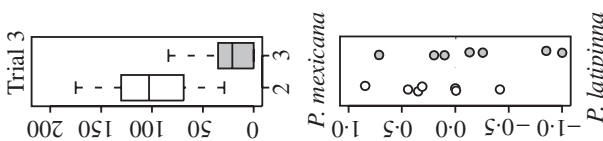

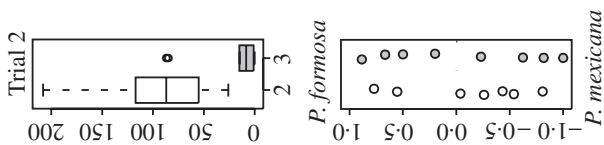

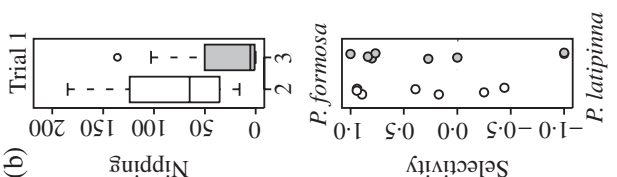

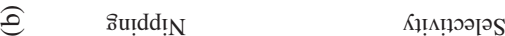

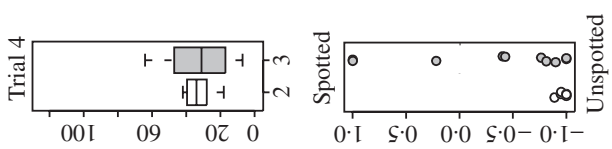

言

응을

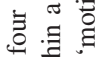

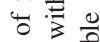

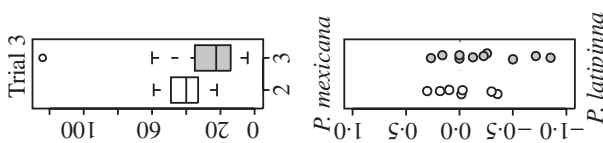

븤

过

幽 䒕

के
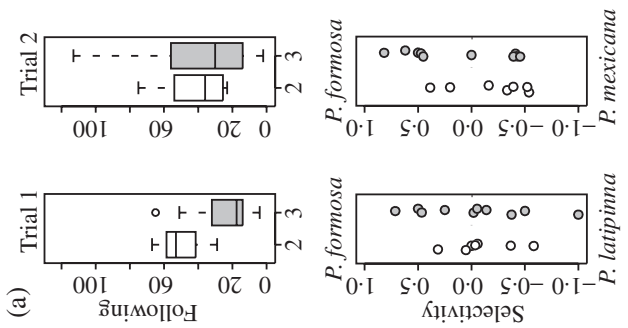
TABLE IV. Group means of the total numbers of the three behavioural elements measured in full contact tests between diploid $\mathrm{F}_{1}$ hybrid males (2) and triploid Poecilia formosa males (3) resembling motivation. Corresponding test results of the Friedman test between both groups are given below

\begin{tabular}{lcccc}
\hline Trial & Ploidy & Following & Nipping & Copulation \\
\hline 1 P. formosa v. Poecilia latipinna & 2 & $49 \cdot 9$ & $83 \cdot 6$ & $69 \cdot 7$ \\
& 3 & $25 \cdot 2$ & $34 \cdot 6$ & $22 \cdot 7$ \\
2 P. formosa v. Poecilia mexicana & 2 & $41 \cdot 9$ & $95 \cdot 0$ & $69 \cdot 0$ \\
& 3 & $38 \cdot 0$ & $22 \cdot 2$ & $13 \cdot 8$ \\
3 P. latipinna v. P. mexicana & 2 & $40 \cdot 7$ & $100 \cdot 9$ & $86 \cdot 0$ \\
& 3 & $34 \cdot 3$ & $26 \cdot 1$ & $16 \cdot 6$ \\
4 Spotted $v$. unspotted & 2 & $32 \cdot 7$ & $52 \cdot 4$ & $46 \cdot 3$ \\
Friedman test (d.f. $=1)$ & 3 & $32 \cdot 8$ & $16 \cdot 0$ & $7 \cdot 9$ \\
& $P$-value & $>0 \cdot 05$ & $<0 \cdot 05$ & $<0 \cdot 05$ \\
\hline
\end{tabular}

recorded [Fig. 6(c)], and only one diploid male nipped only once on a spotted female [Fig. 6(b)]. In contrast to Ptacek (2002), neither hybrid males nor $P$. formosa males showed courtship display.

\section{DISCUSSION}

In most of the unisexual vertebrate complexes, rare phenotypic males have been described, e.g. in Darevskia lizards (Darevski et al., 1978, 1986; Kupriyanova, 1989), as well as in teleosts such as Carassius gibelio (Bloch) (Abramenko et al., 1998), Squalius alburnoides (Steindachner) (Alves et al., 1999), Phoxinus eos-neogaeus (Cope) (Goddard \& Dawley, 1990), Cobitis sp. (Vasil'ev et al., 2003) and Misgurnus anguillicaudatus (Cantor) (Morishima et al., 2004; Itono et al., 2006). Their occurrence does raise several questions: Are these males functional? If so, does their occurrence have consequences for the breeding complex? Are these phenomena linked to sex determination and dispensable genes?

Here, allotriploid males in the unisexual species P. formosa are described, in order to evaluate their functionality (physiologically and behaviourally), and therefore their potential evolutionary significance for the breeding complex. Besides the pigmentation pattern, there were no striking differences between the triploid P. formosa males and the $\mathrm{F}_{1}$ hybrid males in morphological traits. Poecilia formosa males showed the typical male phenotype, including body proportions as well as yellowish pigmentation of the fins. The expression of the microchromosome-specific pigmentation locus, however, changes the overall appearance of these males, which might have an effect on female mate choice. The pigmentation pattern was always less pronounced than in their diploid mothers. The expression of the pigmentation gene of the microchromosome may be differentially modified by the presence or absence of a third chromosome set as shown by Pala et al. (2008) for gene expression in allotriploid S. alburnoides.

All P. formosa males possessed a fully differentiated suspensorium and gonopodium. The number of subdistal serrae of ray $4 p$ varied within as well as 
between the different male types and deviated slightly from those reported by Dramsch (1977) or Döbler (1998). Showing all features of the anatomy of the complex insemination apparatus of poeciliids, it is inferred, however, that triploid $P$. formosa males can be classified as functional males.

Although triploid P. formosa males show the typical testis morphology, they differ strikingly from normal males in the number of mature spermatozoa. Analysing DNA content and ploidy level of testis cells by IOD revealed a reduced number of $6 \mathrm{C}$ cells, as well as aneuploid sperm. The data may be explained by the fact that after the G2 of meiosis daughter cells with aneuploid numbers of chromosomes are formed resulting in aneuploid sperm. As a result, spermatogenesis is impaired, meiosis arrested at S2 and most cysts in triploid males remain in the spermatogonial and spermatocyte stages. Because of this difficulty of equally distributing three chromosome sets in meiosis, sexual reproduction of triploids is usually impossible. This is corroborated by the fact that no offspring were obtained with sexual $P$. mexicana females but only with $P$. formosa females for which chromosome balance does not play a pivotal role for only activating embryonic development.

In the behavioural choice tests neither of the two different male types showed a significant preference for females of either species. Given the choice between a male and a female, however, each male type preferred the male. Therefore, the comparison of the two types of males revealed no significant difference. Sexual selection involves two main mechanisms: intrasexual competition for mates (intermale competition) and intersexual mate choice. Balsano et al. (1985) demonstrated that dominant P. mexicana males direct $63 \%$ of their activities to other males, and only $37 \%$ to females. As the $P$. formosa males and $\mathrm{F}_{1}$ hybrid males have been kept solitarily during the daily tests, it was assumed that they showed (probably sexual) dominance behaviour towards males. This is an important finding that could not be achieved by full contact tests.

The only significant difference between the triploid $P$. formosa males and the diploid $\mathrm{F}_{1}$ hybrid males was found in the trial of spotted $v$. wild-type $P$. formosa. The $F_{1}$ hybrid males spent significantly more time in front of the wild-type female and interacted more with it. Poecilia formosa males, however, did not choose clearly between the two female types but tended to prefer the spotted females. This interpretation gets further support from the fact that the triploid $P$. formosa males predominantly produced offspring with spotted P. formosa females. Landeau \& Terborgh (1986) and Theodorakis (1989) showed that phenotypically different individuals are prone to higher predation risk (oddity effect). Therefore, given the choice, an individual should decide to shoal with similar individuals, a pattern which McRobert \& Bradner (1998) and Ledesma \& McRobert (2008) were able to show by studying bright and dark P. latipinna (Blakeslee et al. 2008; Gómez-Laplaza, 2009). Whether this is the case also in choosing a mating partner is not clear. Another possible explanation could be that the males chose a familiar stimulus. Since the triploid $P$. formosa males, in contrast to the diploid $\mathrm{F}_{1}$ hybrid males, had been raised with their spotted as well as unspotted (= wild-type) sisters, experience could have influenced the mate choice (Magurran et al., 1994; Körner et al., 1999). This has to be studied more intensively. 
Overall, no significant differences in the selectivity of $P$. formosa males and $\mathrm{F}_{1}$ hybrid males were found. This was cautiously interpreted as absence of major differences. Clearly the analysis is limited through small sample sizes but, as shown in the preference test of spotted $v$. wild-type P. formosa, differences can be resolved even with this small sample number. Thus, the findings indicate that the $P$. formosa males described here are capable of typical male behaviour and should be viewed as functional males in this respect. They showed, however, a reduced motivation to perform different types of sexual behaviour (i.e. total presenting time, total number of following, nipping and copulation attempts) in comparison to $\mathrm{F}_{1}$ hybrid males. The lower overall sexual activity of $P$. formosa males may be due to lower androgen levels, but may also reflect a loss of genes coding for male characteristics. Different studies have shown that 11-ketotestosterone (11-KT) plays an important role for triggering the male sexual behaviour (Borg, 1987; Brantley et al., 1993). Oligospermy in combination with lower sexual motivation might therefore be the reason for the low breeding success of the triploid $P$. formosa males (only five males out of 16 sired offspring).

Sex steroids are classically known to operate through two distinct mechanisms to affect physiology and behaviour in vertebrates: organizational (dimorphic differentiation of brain morphology during ontogeny) and activational (effects on fully developed nervous system) (Cooke et al., 1998). The 'selectivity component' should reflect the organizational effect (i.e. development) of the brain. Since there is just one clear difference in 'selectivity' in the test 'spotted $v$. unspotted' (possibly simply because diploid fish were not habituated to spotted fish), it seems that malespecific imprinting of the brain has taken place during ontogeny of the triploid $P$. formosa males. The high and consistent difference in frequency of the according behaviour, however, points towards lower activational mechanisms (i.e. actual hormone level).

In rare cases, phenotypic males of $P$. formosa have been observed in natural habitats (Hubbs et al., 1959; Hubbs, 1964; Darnell \& Abramoff, 1968; Döbler, 1998). Their ploidy and presence of microchromosomes, however, was never investigated, and in some cases their hybrid character cannot be ruled out (Schlupp et al., 1992). Provided that the P. formosa males occurring in nature are also triploid and have similar properties to those described in the present paper (triploid with microchromosome), the intriguing question arises whether their inadequate meiotic performance, presumably resulting in aneuploid sperm, may still have some evolutionary significance under the special rules of gynogenesis. In Lamatsch et al. (2000a) and this study, it is shown that aneuploid sperm is able to function quite adequately as a trigger in gynogenesis. If this is true, gynogenetic lineages may sometimes become at least partly independent from their sexual hosts. Despite their low frequency under laboratory conditions, conclusions about frequencies in nature cannot be drawn. Natural populations of P. formosa, however, are large, therefore increasing the probability to obtain males. Unfortunately, males found in nature have not been quantitatively and qualitatively investigated. A survey of natural habitats for males and subsequent investigation of their karyotype is underway (I. Schlupp, pers. comm.).

Despite their potential evolutionary significance, the question of what are the sex-determining factors leading to these unusual triploid males in an otherwise allfemale species cannot be answered yet. Is it the additional chromosome set or the 
macromelanophore locus-containing microchromosome (Schartl et al., 1997) or the combination of both? In X. maculatus, it has been shown that gene loci involved in different pigmentation patterns and in sexual maturity are closely linked to the sex-determining locus in the subtelomeric region of the $\mathrm{X}$ - and $\mathrm{Y}$-chromosomes (Kallman, 1984; Gutbrod \& Schartl, 1999). The presence of the microchromosome alone, however, is unlikely to explain the occurrence of males since none of the diploid spotted individuals has ever developed a male phenotype. In addition, the third chromosome set alone is not sufficient to cause a sex reversal since all unspotted triploids detected were females (Monaco et al., 1984; Nanda et al., 1995; Lamatsch et al., 2000b, 2004). Therefore, the combination of both, an additional chromosome set and the macromelanophore locus-containing microchromosome, are probably necessary for the male development. To what extent the microchromosome and the third genome influence the sex determination in an otherwise all-female species will be the subject of future studies.

Special thanks go to H. Schwind, G. Schneider and P. Weber for breeding the fishes in the laboratory and detecting the males. We thank R. Butlin and D. Cameron, University of Sheffield, for constructive comments and language improvement, and K. Lampert for fruitful discussions. A. Chadt, M. Hidding and W. Plendl helped with the behavioural choice tests. We thank T. Klapperstück, Klinik für Dermatologie und Venerologie, MartinLuther-Universität Halle-Wittenberg, for the opportunity to use CYDOK and for providing software for the analysis of densitometric data. Financial support for this study was granted by the DFG (SFB 567 'Mechanismen der interspezifischen Interaktion von Organismen'), and Fonds der Chemischen Industrie. I.S. was supported by a Heisenberg Fellowship. The manuscript was greatly improved by the constructive comments of four anonymous reviewers.

\section{References}

Abramenko, M. I., Poltavseva, T. G. \& Vasetskii, S. G. (1998). Discovery of triploid males in lower Don populations of the crucian carp Carassius auratus gibelio (Bloch). Doklady Akademii Nauk 363, 415-418.

Abramoff, P., Darnell, R. M. \& Balsano, J. S. (1968). Electrophoretic demonstration of the hybrid origin of the gynogenetic teleost Poecilia formosa. The American Naturalist 102, 555-558.

Altmann, J. (1974). Observational study of behavior: sampling methods. Behaviour 49, $227-267$.

Alves, M. J., Coelho, M. M., Prospero, M. I. \& Collares-Pereira, M. J. (1999). Production of fertile unreduced sperm by hybrid males of the Rutilus alburnoides complex (Teleostei, cyprinidae). An alternative route to genome tetraploidization in unisexuals. Genetics 151, 277-283.

Avise, J. C., Trexler, J. C., Travis, J. \& Nelson, W. S. (1991). Poecilia mexicana is the recent female parent of the unisexual fish $P$. formosa. Evolution 45, 1530-1533.

Balsano, J. S., Randle, E. J., Rasch, E. M. \& Monaco, P. J. (1985). Reproductive behavior and the maintenance of all-female Poecilia. Environmental Biology of Fishes 12, $251-263$.

Beukeboom, L. W. \& Vrijenhoek, R. C. (1998). Evolutionary genetics and ecology of spermdependent parthenogenesis. Journal of Evolutionary Biology 11, 755-782.

Bisazza, A. (1993). Male competition, female mate choice and sexual size dimorphism in poeciliid fishes. In Behavioural Ecology of Fishes (Huntingford, F. A. \& Torrycelli, P., eds), pp. 257-286. Erice: CRC Press.

Blakeslee, C., McRobert, S. P., Brown, A. C. \& Clotfelter, E. D. (2008). The effect of body coloration and group size on social partner preferences in female fighting fish (Betta splendens). Behavioural Processes 80, 157-161. 
Borg, B. (1987). Stimulation of reproductive behaviour by aromatizable and non-aromatizable androgens in male three-spined stickleback, Gasterosteus aculeatus L. In Proceedings of the 5th Congress of European Ichthyologists Stockholm 1985 (Kullander, S. O. \& Fernholm, B., eds), pp. 269-271. Stockholm: Swedish Museum of Natural History.

Brantley, R. K., Wingfield, J. C. \& Bass, A. H. (1993). Sex steroid levels in Porichthys notatus, a fish with alternative reproductive tactics, and a review of the hormonal bases for male dimorphism among teleost fishes. Hormones and Behavior 27, 332-347.

Choleva, L., Apostolou, A., Rab, P. \& Janko, K. (2008). Making it on their own: spermdependent hybrid fishes (Cobitis) switch the sexual hosts and expand beyond the ranges of their original sperm donors. Philosophical Transactions of the Royal Society B 363, 2911-2919.

Cooke, B., Hegstrom, C. D., Villeneuve, L. S. \& Breedlove, S. M. (1998). Sexual differentiation of the vertebrate brain: principles and mechanisms. Frontiers in Neuroendocrinology 19, 323-362.

Culling, C. F. A. (1963). Handbook of Histopathological Techniques. London: Butterworths \& Co Publishers.

Darevski, I. S., Kupriyanova, L. A. \& Bakradze, M. A. (1978). Occasional males and intersexes in parthenogenetic species of Caucasian rock lizards (genus Lacerta). Copeia 1978, 201-207.

Darevski, I. S., Kupriyanova, L. A. \& Danielyan, F. D. (1986). New evidence of hybrid males in a parthenogenetic lizard. In Studies in Herpetology Proceedings of the European Congress of Herpetology (Rocek, P., ed.), pp. 277-312. Prague: Societas Europaea Herpetologica.

Darnell, R. M. \& Abramoff, P. (1968). Distribution of the gynogenetic fish, Poecilia formosa, with remarks on the evolution of the species. Copeia 1968, 354-361.

Dawson, A. B. (1926). A note on the staining of the skeleton of cleared specimens with Alizarin Red S. Biotechnic and Histochemistry 1, 123-124.

Döbler, M. (1998). Zum Fortpflanzungsmodus des Amazonenkärpflings (Poecilia formosa (Girard 1859)). PhD Thesis, Universität Hamburg, Germany.

Dramsch, W. (1977). Gynogenese bei P. formosa. Das Verhalten künstlich erzeugter Männchen und die Konsequenzen für die systematische Stellung dieser Art. PhD Thesis, Universität Hamburg, Germany.

Franck, D. (1975). Der Anteil des "Coolige-Effektes" an der isolationsbedingten Zunahme sexueller Verhaltensweisen von Poecilia shenops. Zeitschrift für Tierpsychologie 38, $472-481$.

Franck, D. \& Geissler, U. (1973). Experiments on the change of sexual responsiveness following short-term social isolation in Xiphophorus helleri. Zeitschrift für Tierpsychologie 33, 408-416.

Gabor, C. R. \& Aspbury, A. S. (2008). Non-repeatable mate choice by male Sailfin mollies, Poecilia latipinna, in a unisexual-bisexual mating complex. Behavioural Ecology 19, $871-878$.

Goddard, K. A. \& Dawley, R. M. (1990). Clonal inheritance of a diploid nuclear genome by a hybrid freshwater minnow (Phoxinus eos-neogaeus, Pisces: Cyprinidae). Evolution 44, $1052-1065$.

Gómez-Laplaza, L. M. (2009). Recent social environment affects colour-assortative shoaling in juvenile angelfish (Pterophyllum scalare). Behavioural Processes 82, 39-44.

Gutbrod, H. \& Schartl, M. (1999). Intragenic sex-chromosomal crossovers of Xmrk oncogene alleles affect pigment pattern formation and the severity of melanoma in Xiphophorus. Genetics 151, 773-783.

Hamaguchi, S. \& Egami, N. (1980). The male secondary sex characteristics in the gynogenetic female fish, Poecilia formosa, induced by the administration of methyltestosterone. Annotationes Zoologicae Japonenses 53, 227-230.

Haskins, C. P., Haskins, E. F. \& Hewitt, R. E. (1960). Pseudogamy as an evolutionary factor in the poeciliid fish Mollienisia formosa. Evolution 14, 473-483.

Hubbs, C. (1964). Interactions between a bisexual fish species and its gynogenetic sexual parasite. Bulletin of the Texas Memorial Museum 8, 1-72.

Hubbs, C. L. \& Hubbs, L. C. (1932). Apparent parthenogenesis in nature, in a form of fish of hybrid origin. Science 76, 628-630. 
Hubbs, C., Drewry, G. E. \& Warburton, B. (1959). Occurrence and morphology of a phenotypic male of a gynogenetic fish. Science 129, 1227-1229.

Itono, M., Morishima, K., Fujimoto, T., Bando, E., Yamaha, E. \& Arai, K. (2006). Premeiotic endomitosis produces diploid eggs in the natural clone loach, Misgurnus anguillicaudatus (Teleostei: Cobitidae). Journal of Experimental Zoology 305A, 513-523.

Kallman, K. D. (1975). The platyfish, Xiphophorus maculates. In Handbook of Genetics (King, R. C., ed.), pp. 81-132. New York, NY: Plenum Publishing Corp.

Kallman, K. D. (1984). A new look at sex determination in Poeciliid fish. In Evolutionary Genetics of Fishes (Turner, B. J., ed.), pp. 95-171. New York, NY: Plenum Press.

Klapperstück, T. \& Wohlrab, W. (1996). DNA image cytometry on sections as compared with image cytometry on smears and flow cytometry in melanoma. Cytometry 25, $82-89$.

Kodrik-Brown, A. (1989). Dietary carotenoids and male mating success: an environmental component of female choice. Behavioral Ecology and Sociobiology 25, 393-401.

Körner, K. E., Luetjens, O., Parzefall, J. \& Schlupp, I. (1999). The role of experience in mating preferences of the unisexual Amazon molly. Behaviour 136, 257-268.

Kupriyanova, L. A. (1989). Cytogenetic evidence for genome interaction in hybrid lacertid lizards. In Evolution and Ecology of Unisexual Vertebrates (Dawley, R. M. \& Bogart, J. P., eds), pp. 236-240. Albany, NY: New York State Museum.

Lamatsch, D. K. (2001). Molecular and cytogenetic investigations on paternal leakage in the sperm-dependent parthenogen, Poecilia formosa. PhD Thesis, University of Wuerzburg, Germany.

Lamatsch, D. K. \& Stöck, M. (2009). Sperm-dependent parthenogenesis and hybridogenesis in teleost fishes. In Lost Sex-The Evolutionary Biology of Parthenogenesis (Martens, K., Schön, I. \& van Dijk, P., eds), pp. 399-432. Dordrecht: Springer.

Lamatsch, D. K., Nanda, I., Epplen, J. T., Schmid, M. \& Schartl, M. (2000a). Unusual triploid males in a microchromosome-carrying clone of the Amazon molly, Poecilia formosa. Cytogenetics and Cell Genetics 91, 148-156.

Lamatsch, D. K., Steinlein, C., Schmid, M. \& Schartl, M. (2000b). Non-invasive determination of genome size and ploidy level in fishes by flow cytometry: detection of triploid Poecilia formosa. Cytometry 39, 91-95.

Lamatsch, D. K., Nanda, I., Schlupp, I., Epplen, J. T., Schmid, M. \& Schartl, M. (2004). Distribution and stability of supernumerary microchromosomes in natural populations of the Amazon molly, Poecilia formosa. Cytogenetic and Genome Research 106, 189-194.

Lamatsch, D. K., Lampert, K. P., Fischer, P., Geiger, M., Schlupp, I. \& Schartl, M. (2009). Diploid Amazon mollies (Poecilia formosa) show a higher fitness than triploids in clonal competition experiments. Evolutionary Ecology 23, 687-697.

Lampert, K. P. \& Schartl, M. (2008). The origin and evolution of a unisexual hybrid: Poecilia formosa. Philosophical Transactions of the Royal Society B 363, 2901-2909.

Lampert, K. P., Lamatsch, D. K., Fischer, P., Epplen, J. T., Nanda, I., Schmid, M. \& Schartl, M. (2007). Automictic reproduction in interspecific hybrids of Poeciliid fish. Current Biology 17, 1948-1953.

Landeau, L. \& Terborgh, J. (1986). Oddity and the "confusion effect" in predation. Animal Behaviour 34, 1372-1380.

Ledesma, J. M. \& McRobert, S. P. (2008). Innate and learned shoaling preferences based on body coloration in juvenile mollies, Poecilia latipinna. Ethology 114, 1044-1048.

Magurran, A. E., Seghers, B. H., Shaw, P. W. \& Carvalho, G. R. (1994). Schooling preferences for familiar fish in the guppy, Poecilia reticulata. Journal of Fish Biology 45, 401-406. doi: 10.1111/j.1095-8649.1994.tb01322.x

McRobert, S. P. \& Bradner, J. (1998). The influence of body coloration on shoaling preferences in fish. Animal Behaviour 56, 611-615.

Monaco, P. J., Rasch, E. M. \& Balsano, J. S. (1984). Apomictic reproduction in the Amazon molly, Poecilia formosa, and its triploid hybrids. In Evolutionary Genetics of Fishes (Turner, B. J., ed.), pp. 311-328. New York, NY: Plenum Press.

Morishima, K., Oshima, K., Horie, S., Fujimoto, T., Yamaha, E. \& Arai, K. (2004). Clonal diploid sperm of the diploid-triploid mosaic loach, Misgurnus anguillicaudatus (Teleostei: Cobitidae). Journal of Experimental Zoology 301A, 502-511. 
Nanda, I., Schartl, M., Feichtinger, W., Schlupp, I., Parzefall, J. \& Schmid, M. (1995). Chromosomal evidence for laboratory synthesis of a triploid hybrid between the gynogenetic teleost Poecilia formosa and its host species. Journal of Fish Biology 47, 619-623. doi: 10.1111/j.1095-8649.1995.tb01928.x

Nanda, I., Schlupp, I., Lamatsch, D. K., Lampert, K. P., Schmid, M. \& Schartl, M. (2007). Stable inheritance of host species-derived microchromosomes in the gynogenetic fish, Poecilia formosa. Genetics 177, 917-926.

Niemeitz, A., Kreutzfeld, R., Schartl, M., Parzefall, J. \& Schlupp, I. (2002). Male mating behaviour of a molly, Poecilia latipunctata: a third host for the sperm-dependent Amazon molly, Poecilia formosa. Acta Ethologica 5, 45-49.

Pala, I., Coelho, M. M. \& Schartl, M. (2008). Dosage compensation by gene-copy silencing in a triploid hybrid fish. Current Biology 18, 1344-1348.

Parzefall, J. (1969). Zur vergleichenden Ethologie verschiedener Mollienesia-Arten einschließlich einer Höhlenform von M. sphenops. Behaviour 33, 1-38.

Parzefall, J. (1973). Attraction and sexual cycle of Poeciliids. In Genetics and Mutagenesis of Fish (Schröder, J. H., ed.), pp. 177-183. Berlin: Springer.

Peden, A. E. (1973). Variation in the anal spot expression of Gambusiin females and its affect on male courtship. Copeia 1973, 250-263.

Ptacek, M. B. (2002). Patterns of inheritance of mating signals in interspecific hybrids between Sailfin and Shortfin mollies (Poeciliidae: Poecilia: Mollienesia). Genetica 116, 329-234.

Rosen, D. E. \& Bailey, R. M. (1963). The poeciliid fishes (Cyprinodontiformes), their structure, zoogeographie, and systematics. Bulletin of the American Museum of Natural History 126, 1-176.

Schartl, M., Schlupp, I., Schartl, A., Meyer, M. K., Nanda, I., Schmid, M., Epplen, J. T. \& Parzefall, J. (1991). On the stability of dispensable constituents of the eukaryotic genome: stability of coding sequences versus truly hypervariable sequences in a clonal vertebrate, the Amazon molly, Poecilia formosa. Proceedings of the National Academy of Sciences the United States of America 88, 8759-8763.

Schartl, M., Wilde, B., Schlupp, I. \& Parzefall, J. (1995a). Evolutionary origin of a parthenoform, the Amazon molly Poecilia formosa, on the basis of a molecular genealogy. Evolution 49, 827-835.

Schartl, M., Nanda, I., Schlupp, I., Wilde, B., Epplen, J. T., Schmid, M. \& Parzefall, J. (1995b). Incorporation of subgenomic amounts of DNA as compensation for mutational load in a gynogenetic fish. Nature 373, 68-71.

Schartl, A., Hornung, U., Nanda, I., Wacker, R., Muller-Hermelink, H. K., Schlupp, I., Parzefall, J., Schmid, M. \& Schartl, M. (1997). Susceptibility to the development of pigment cell tumors in a clone of the Amazon molly, Poecilia formosa, introduced through a microchromosome. Cancer Research 57, 2993-3000.

Schlupp, I. (2005). The evolutionary ecology of gynogenesis. Annual Review of Ecology, Evolution, and Systematics 36, 399-417.

Schlupp, I. \& Ryan, M. J. (1996). Mixed-species shoals and the maintenance of a sexualasexual mating system in mollies. Animal Behavior 52, 885-890.

Schlupp, I., Parzefall, J. \& Schartl, M. (1991). Male mate choice in mixed bisexual/unisexual breeding complexes of Poecilia (Teleostei; Poeciliidae). Ethology 88, 215-222.

Schlupp, I., Parzefall, J., Epplen, J. T., Nanda, I., Schmid, M. \& Schartl, M. (1992). Pseudomale behaviour and spontaneous masculinization in the all-female teleost Poecilia formosa (Teleostei: Poeciliidae). Behaviour 122, 88-104.

Schlupp, I., Marler, C. \& Ryan, M. J. (1994). Benefit to male Sailfin mollies of mating with heterospecific females. Science 263, 373-374.

Schlupp, I., Nanda, I., Dobler, M., Lamatsch, D. K., Epplen, J. T., Parzefall, J., Schmid, M. \& Schartl, M. (1998). Dispensable and indispensable genes in an ameiotic fish, the Amazon molly Poecilia formosa. Cytogenetics and Cell Genetics 80, $193-198$.

Schröder, J. H. (1964). Genetische Untersuchungen an domestizierten Stämmen der Gattung Mollienesia (Poeciliidae). Zoologische Beiträge 10, 369-463.

Stöck, M. \& Grosse, W.-R. (1997). Erythrocyte size and ploidy determination in green toads (Bufo viridis complex) from Middle Asia. Alytes (Paris) 15, 72-90. 
Stöck, M., Lamatsch, D. K., Steinlein, C., Epplen, J. T., Grosse, W. R., Hock, R., Klapperstuck, T., Lampert, K. P., Scheer, U., Schmid, M. \& Schartl, M. (2002). A bisexually reproducing all-triploid vertebrate. Nature Genetics 30, $325-328$.

Theodorakis, C. W. (1989). Size segregation and the effects of oddity on predation risk in minnow schools. Animal Behaviour 38, 496-502.

Travis, J. (1994). Size-dependent behavioral variation and its genetic control within and among populations. In Quantitative Genetic Studies of Behavioral Evolution (Boake, C. R. B., ed.), pp. 165-187. Chicago, IL: University of Chicago Press.

Travis, J. \& Woodward, B. D. (1989). Social context and courtship flexibility in male sailfin mollies, Poecilia latipinna (Pisces: Poeciliidae). Animal Behaviour 38, 1001-1011.

Turner, B. J. \& Steeves, H. R. (1989). Induction of spermatogenesis in an all-female fish species by treatment with an exogenous androgen. In Evolution and Ecology of Unisexual Vertebrates (Dawley, R. M. \& Bogart, J. B., eds), pp. 113-122. New York, NY: New York State Museum.

Turner, B. J., Brett, B. H. \& Miller, R. R. (1980). Interspecific hybridization and the evolutionary origin of a gynogenetic fish, Poecilia formosa. Evolution 34, 917-922.

Vasil'ev, V. P., Akimova, N. V., Emel'yanova, N. G., Pavlov, D. A. \& Vasil'eva, E. D. (2003). Reproductive capacities in the polyploid males of spined loaches from the unisexual-bisexual complex, occurred in the Moscow River. Folia Biologica (Krakow) 51 (Suppl.), 67-73. 


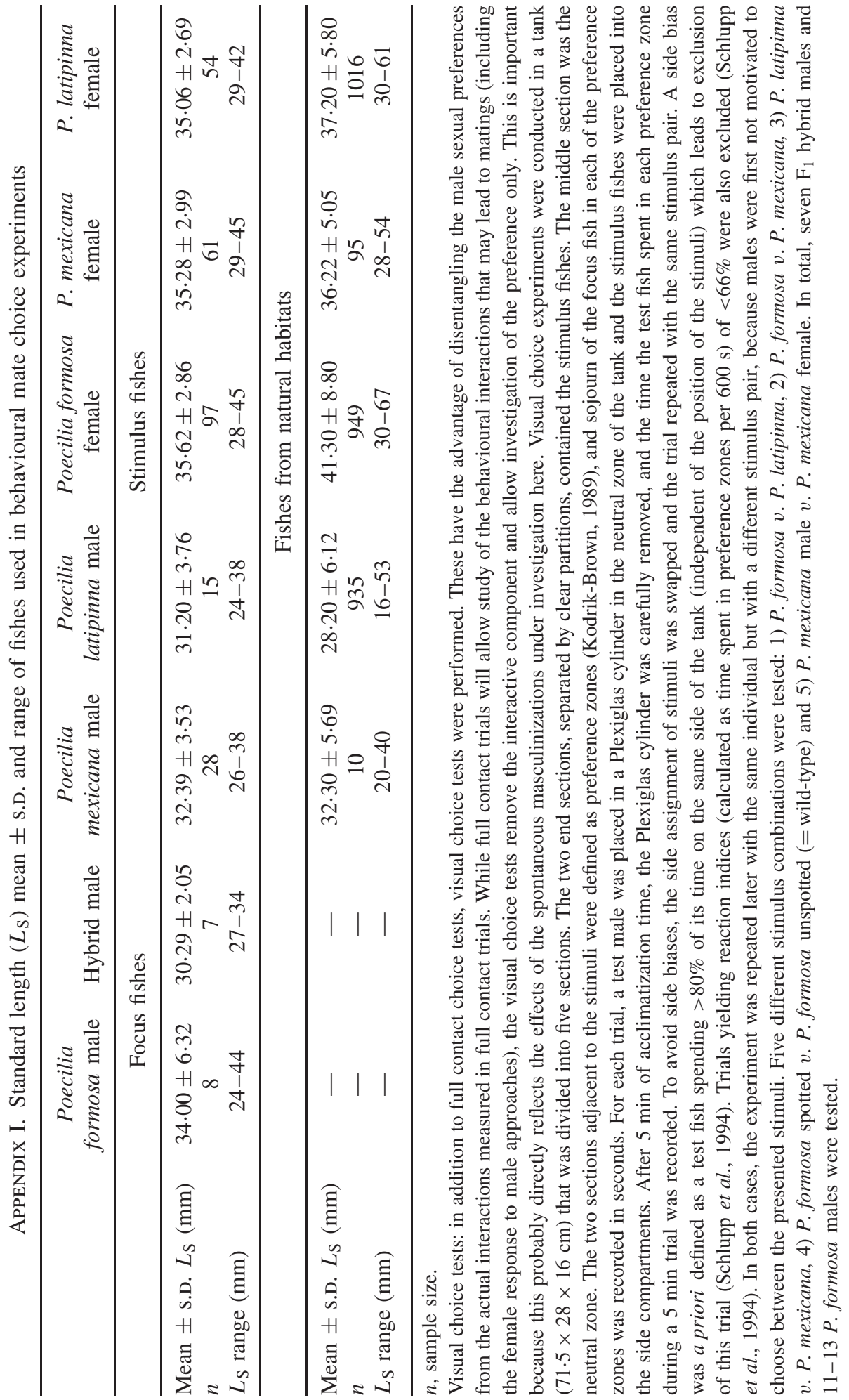




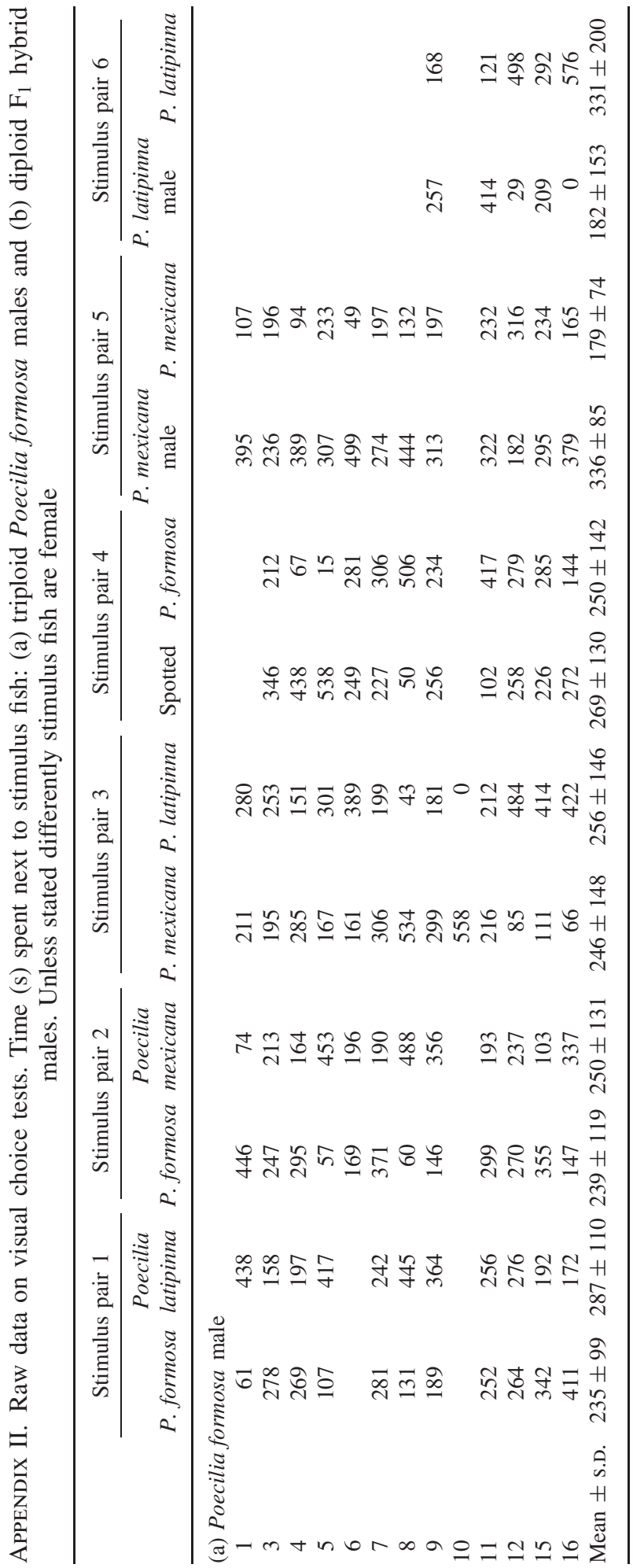




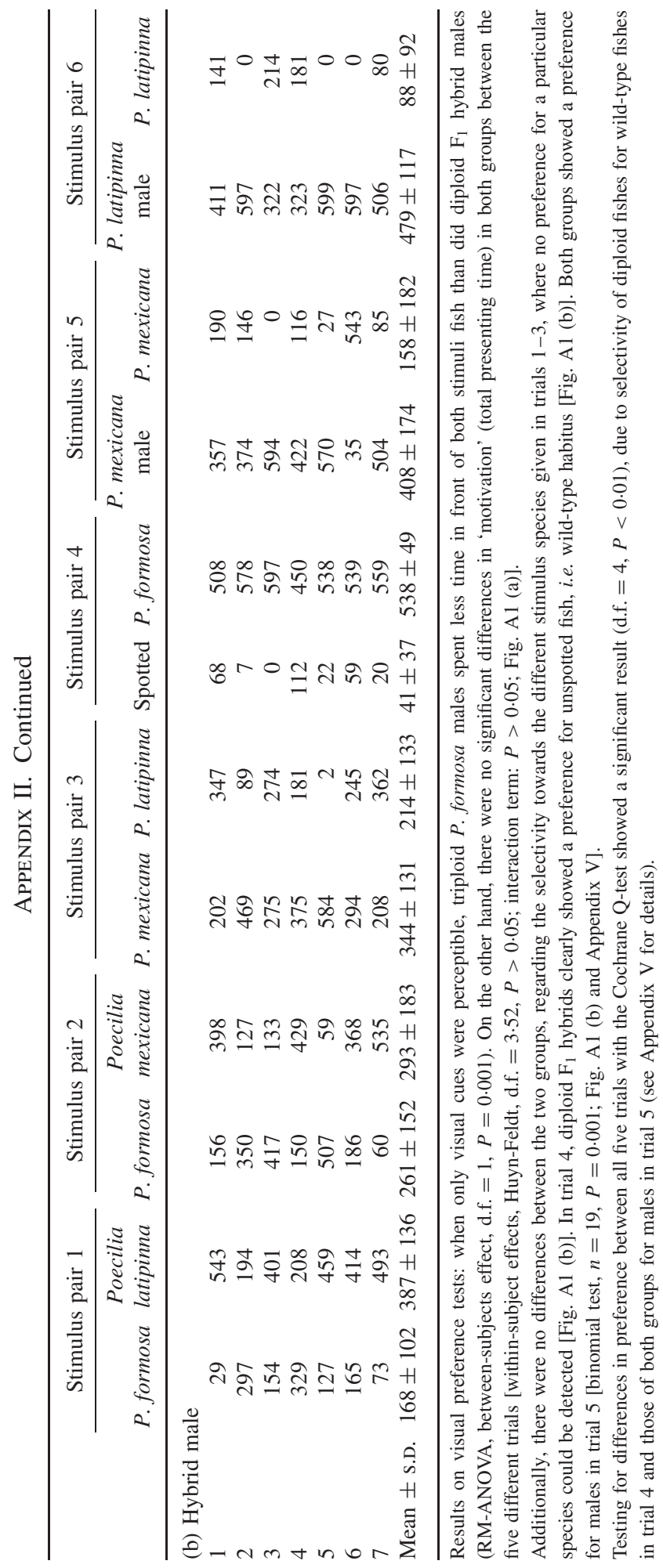




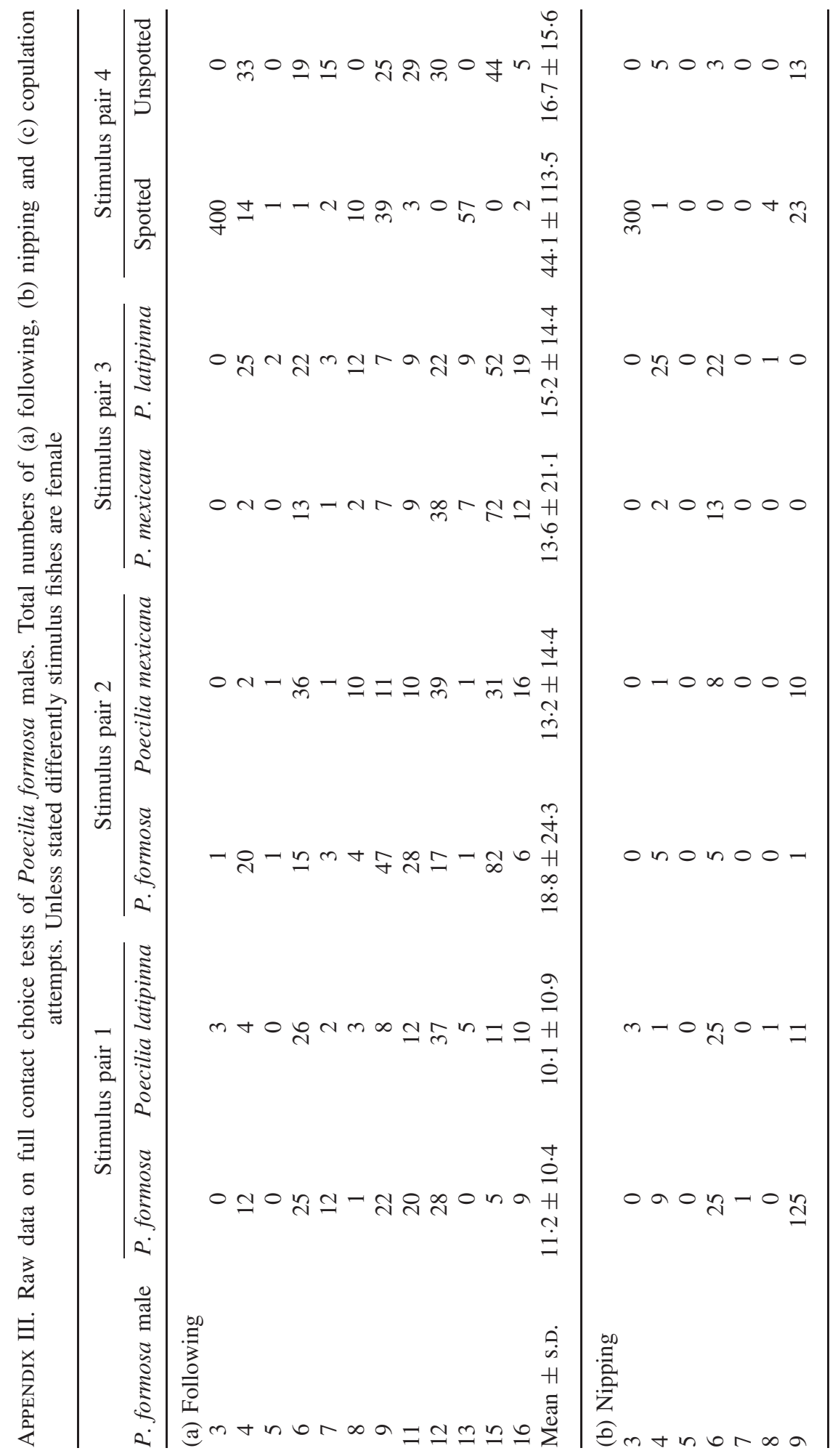




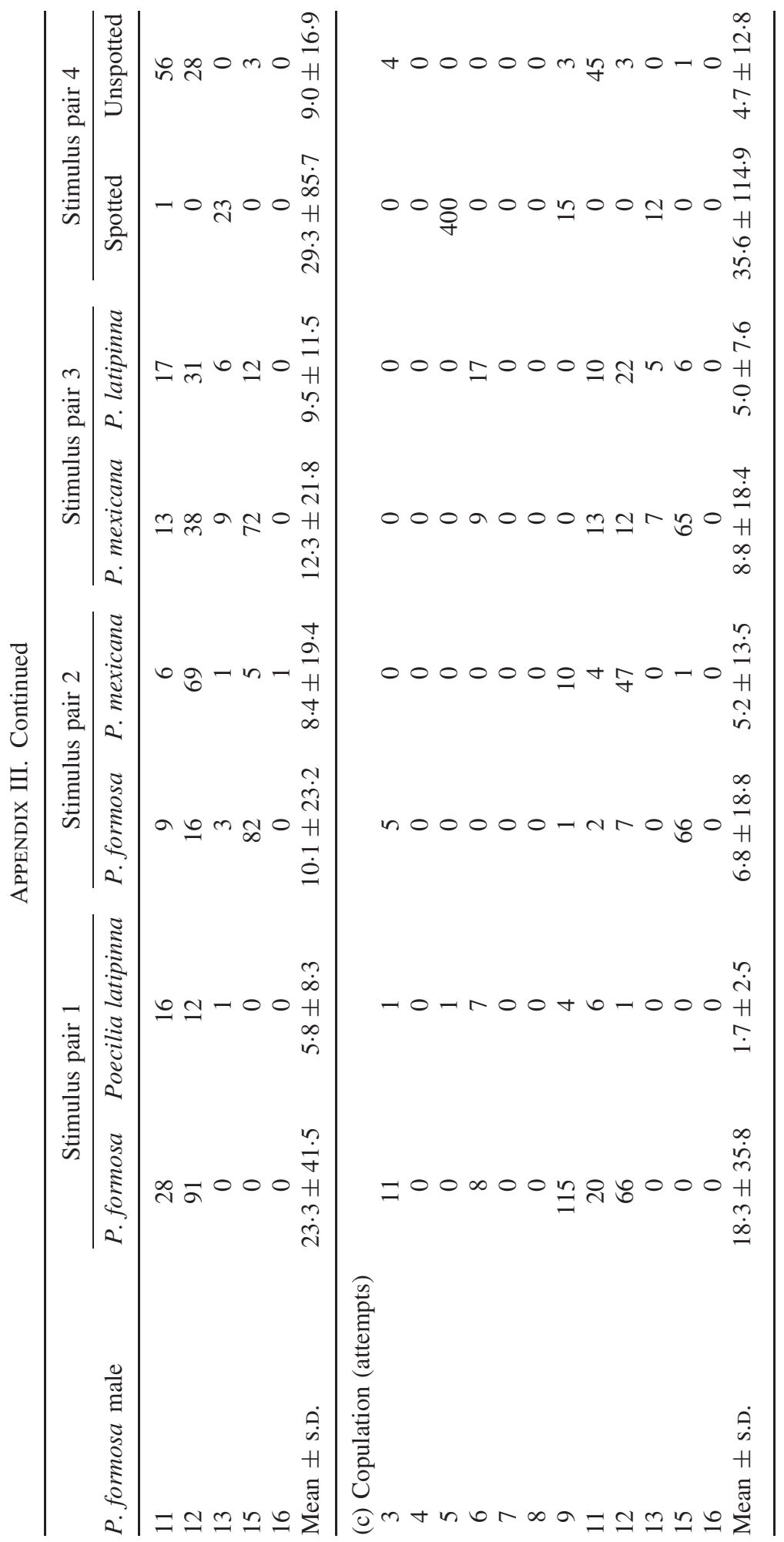




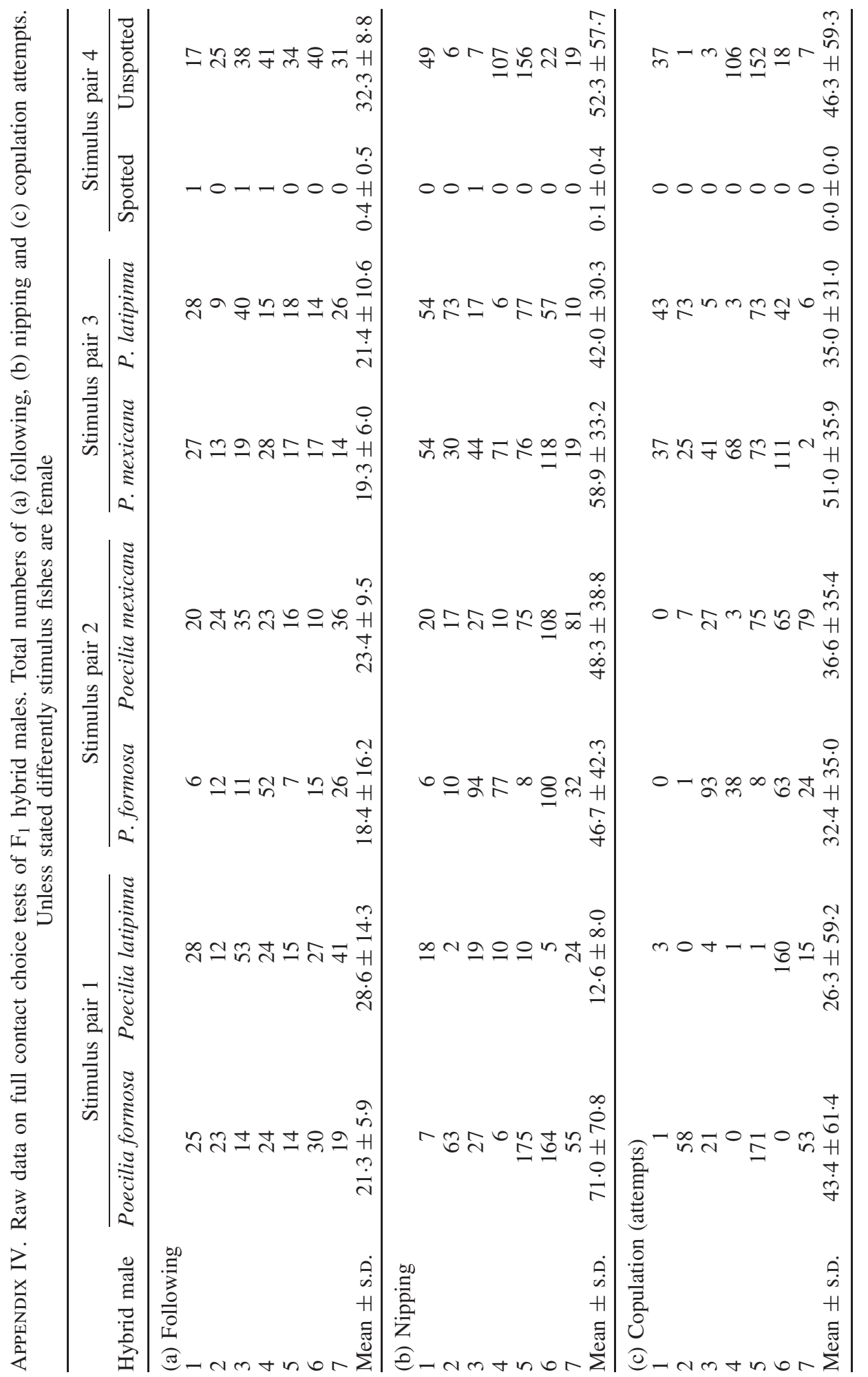


APPENDIX V. Visual choice preferences of the two different groups of males (diploid $F_{1}$ hybrid males, triploid Poecilia formosa males) and overall values are shown for five different stimulus pairs in the visual choice test. $P$-values of the corresponding binomial tests are given to show significant differences in stimulus choice within each trial. Differences in choice between the trials were tested with the Cochran Q test. [Different sample sizes $(n)$ appear because two triploid fish did not perform all different trials due to sudden death.]

\begin{tabular}{|c|c|c|c|c|c|c|c|}
\hline Trial & Stimulus & $\begin{array}{c}n \\
\text { (diploid) }\end{array}$ & $\begin{array}{c}\text { Binomial } \\
P\end{array}$ & $\begin{array}{c}n \\
\text { (triploid) }\end{array}$ & $\begin{array}{c}\text { Binomial } \\
P\end{array}$ & $\begin{array}{c}n \\
\text { (all) }\end{array}$ & $\begin{array}{c}\text { Binomial } \\
P\end{array}$ \\
\hline \multirow[t]{2}{*}{1} & P. formosa & 2 & $>0.05$ & 5 & $>0.05$ & 7 & $>0 \cdot 05$ \\
\hline & Poecilia latipinna & 5 & & 6 & & 11 & \\
\hline \multirow[t]{2}{*}{2} & P. formosa & 3 & $>0.05$ & 7 & $>0.05$ & 10 & $>0 \cdot 05$ \\
\hline & Poecilia mexicana & 4 & & 5 & & 9 & \\
\hline \multirow[t]{2}{*}{3} & P. latipinna & 2 & $>0.05$ & 7 & $>0 \cdot 05$ & 9 & $>0 \cdot 05$ \\
\hline & P. mexicana & 5 & & 5 & & 10 & \\
\hline \multirow[t]{2}{*}{4} & Spotted & 0 & $<0.05$ & 5 & $>0.05$ & 5 & $>0 \cdot 05$ \\
\hline & Unspotted & 7 & & 6 & & 13 & \\
\hline \multirow[t]{2}{*}{5} & Male & 6 & $>0.05$ & 11 & $<0 \cdot 01$ & 17 & $0 \cdot 001$ \\
\hline & Female & 1 & & 1 & & 2 & \\
\hline Cochran Q & & 7 & $<0.01$ & 10 & $>0.05$ & 17 & $<0 \cdot 01$ \\
\hline
\end{tabular}

(a)

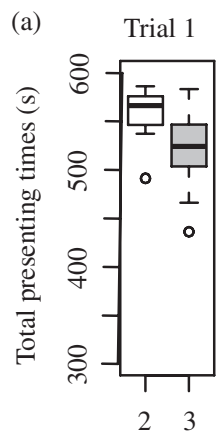

(b)

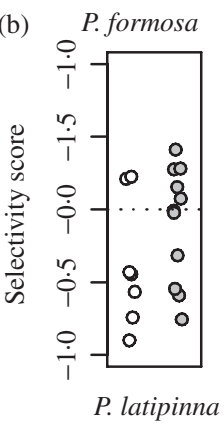

Trial 2
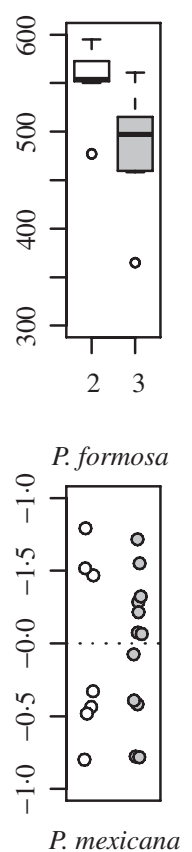

Trial 3
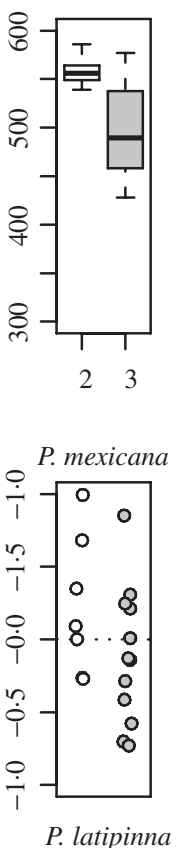

Trial 4
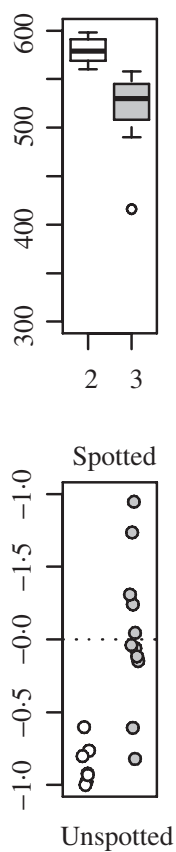

Trial 5
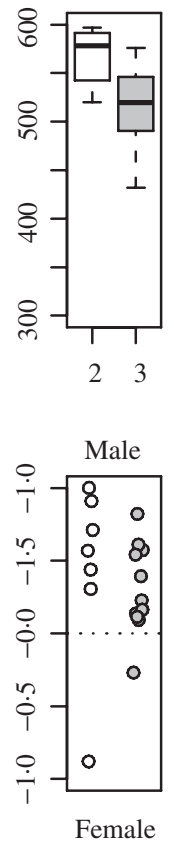

FIG. A1. Results of five visual choice trials with different rivalling stimuli are presented. (a) The total times $\left(\sum t\right)$ of presenting behaviour within a 10 min observation interval, serving as a measure for motivation of the two different groups of males $\left(2 /\right.$ white $=$ diploid $\mathrm{F}_{1}$ hybrid male, $3 /$ grey $=$ triploid Poecilia formosa male). (b) The corresponding selectivity score $\left(\Delta t \sum t^{-1}\right)$ of the individual fish in these trials. Whisker $=$ $1.5 \times$ interquartile range. 